\title{
Estimation of Seismic Ground Motions and Attendant Potential Human Fatalities from a Scenario Earthquake on the Hsincheng Active Fault in Taohsin Area, Taiwan
}

\author{
Kun-Sung Liu ${ }^{1}$, Hsiang-Chi Huang ${ }^{2}$ \\ ${ }^{1}$ Department of Civil Engineering \& Hazard Mitigation Research Center, Kao Yuan University, Kaohsiung, Taiwan, ROC \\ ${ }^{2}$ Department of Public Administration, Tam Kang University, New Taipei City, Taiwan, ROC
}

Email address:

lk.sung99@msa.hinet.net (Kun-Sung Liu), cherry20121224@gmail.com (Hsiang-Chi Huang)

\section{To cite this article:}

Kun-Sung Liu, Hsiang-Chi Huang. Estimation of Seismic Ground Motions and Attendant Potential Human Fatalities from a Scenario Earthquake on the Hsincheng Active Fault in Taohsin Area, Taiwan. Earth Sciences. Vol. 10, No. 2, 2021, pp. 49-63.

doi: $10.11648 /$ j.earth.20211002.12

Received: April 12, 2021; Accepted: April 24, 2021; Published: May 8, 2021

\begin{abstract}
The purpose of this study is to assess seismic hazards in the 29 administration districts of Taohsin area (Taoyuan City, Hsinchu County and Hsinchu City), Taiwan in the form of ShakeMaps as well as to estimate potential human fatalities from a scenario earthquake $\mathrm{Mw} 6.77$ on the Hsincheng active fault in this area. The PGA contour map using historical seismic data and four active faults to calculate the ground motions shows that the areas where the PGA is greater than 400 gal are in the following regions: (1) Southwestern Longtan. (2) Southwestern Hukou, southern Sinfong, southeastern Sinpu, northern and central Jhubei, northern Guansi, central Cyonglin, central Jhudong, western Beipu, southern Baoshan and Emei. (3) The northeastern Bei District and the northern Dong District. Furthermore, the PGV contour map shows that the areas greater than $40 \mathrm{~cm} / \mathrm{s}$ is located in the central Jhubei, western Beipu, southern Baoshan, Emei, and northern and western Dong District of Hsinchu City. In addition, we calculate the probability of earthquake intensity show that the regions with the highest potential for earthquake hazards are located in the area surrounded by Beipu, Baoshan and Emei, as well as the area surrounded by Hukou, Sinfong, Jhubei, Bei Distruct and Xiangshan. The corresponding probability of earthquake intensity exceeding MMI VIII during the period of 50 years is above $35 \%$. Finally, from estimation of potential human fatalities for a scenario earthquake on the Hsincheng fault, the fatalities are 367, 848 and 809 in Taoyuan City, Hsinchu County and Hsinchu City, respectively. Moreover, it is noted that potential fatalities increase rapidly for people above age 45 . Total fatalities reach a high peak in age groups of 5564. Especially, the area surrounded by Jhubei of Hsinchu County, Bei District and Dong District of Hsinchu City with both high population density and high site amplification factor for PGA and PGV, the local governments should be pay more attention on seismic hazard mitigation in this highly urbanized area with large number of buildings.
\end{abstract}

Keywords: Hsincheng Fault, Potential Human Fatality, Ground Motion, Seismic Hazard Potential, Taoyuan, Hsinchu

\section{Introduction}

In accordance with Article 20 of the Disaster Prevention and Protection Act, the implementing units of the Disaster Prevention and Protection Association of municipalities directly under the Municipal/County (City) Governments shall formulate regional disaster prevention and protection plans in accordance with the basic plan for disaster prevention and protection, the relevant business plan for disaster prevention and protection and the potential characteristics of regional disasters. Hence, the purpose of the plan by the local government of Taoyuan and
Hsinchu area is to improve the local disaster prevention and protection system, strengthen disaster prevention and protection work such as pre-disaster disaster reduction, preparation, emergency response in disaster time and post-disaster recovery and reconstruction, with a view to exerting the overall efficiency and effectiveness of disaster relief, and effectively implementing disaster prevention and protection related work at all stages, so as to achieve the goal of rapid disaster relief and disaster loss reduction. In order to make the contents of the regional disaster prevention and protection plan more detailed and in line with the characteristics and needs of the local area, the plan should be 
formulated with the historical disaster factors in mind, and disaster prevention and protection measures should be developed according to the situational setting of the potential of the disaster and the assessment of the damage. This is also our study to explore or solve the problem, that is, to carry out the characteristics of the potential of disaster analysis and damage assessment, for its development of disaster prevention and protection countermeasures.

In the 2010 version of the active fault in Taiwan published by the Central Geological Survey (CGS), there are Hsincheng fault that is classified as the active fault of Category I, as well as the Sanchiao fault, Hukou fault and the Hsinchu fault are classified as the active fault of Category II near or in the Hsinchu and Taoyuan area. Looking back on the past earthquake disaster record of Taoyuan and Hsinchu area, although Taoyuan City rarely has a larger earthquake disaster record, but still cannot be taken lightly. The larger historical earthquake disaster occurred on October 13, 1815, an Ilan offshore earthquake of magnitude 7.6, resulting in the collapse of more than 100 houses in Taoyuan area, about 85 people died for the sake of the houses without earthquake resistance at that time, resulting in such a disaster [1]. The western region of Hsinchu County is densely populated and has developed industrial and commercial construction, so it is easy to cause more serious disasters when a major earthquake occurs. Up to now, the major disasters occurred by an earthquake of magnitude 7.1 on April 21, 1935 in the county. Industrial areas in Hsinchu Prefecture are lined up, and toxic chemicals needed for industrial production may leak out after the earthquake, which is a potential source of earthquake disasters that cannot be ignored. In addition, the Baoshan reservoir dam is only 5 to 6 kilometers away from the Hsincheng fault, which may cause flood damage due to earthquake damage cannot be taken lightly [2]. Hsinchu City has Hsinchu and Hsincheng activity faults through, resulting in the earthquake disaster hidden worry. Furthermore, the Hsinchu Science Park is home to manufacturers storing toxic chemical substances, which, in the event of an explosion or leakage of toxic chemicals, may result in a large number of human casualties and losses [3].

The pre-emulation of seismic disaster scenario needs to analyze the potential of earthquake disaster in this area. In recent years, both domestic and foreign organization have invested in research and development of disaster potential assessment methods, disaster potential analysis and risk assessment, as well as disaster scenario, as the basis for the division of hazardous areas; And improve the guidance of disaster prevention and relief work, which is also the national science and technology program in the sustainable development of disaster prevention priorities. To sum up, the study uses data on 11 disaster earthquakes in Taiwan from 1683 to 1899 , as well as seismic data with a moment magnitude greater than 5 from 1900 to 2019, and the above four active faults to analyze the potential for seismic hazards in the Hsinchu and Taoyuan area. To estimate the seismic maximum ground motions, and the probabilities of exceeded the intensity of Central Weather Bureau (CWB) 5, 6, 7 and Modified Mercalli Intensity (MMI) VI, VII and VIII in 10, 30 and 50 years in a total of 29 administrative districts of Taoyuan City, Hsinchu
County and Hsinchu City is analyzed, as well as the seismic disaster situation in this area is further simulated. We will assess potential death tolls due to future great earthquakes occurring on the Hsincheng active fault. The results of this study can be used to understand the distribution of high earthquake hazard potential areas in Hsinchu and Taoyuan area, to provide the reference for earthquake-resistant design of plants for important economic construction, and to develop the basis of earthquake prevention and emergency response plans for Taoyuan City, Hsinchu County and Hsinchu City.

\section{The Study Area and Data Used}

The area of our study is the Hsinchu and Taoyuan area, the study area and corresponding distribution of active faults as shown in Figure 1. Among them, the Sanchiao fault is a normal and strike-slip fault of north-north east direction, can be divided into two sections: the southern section from the Shulin District of New Taipei City to Beitou District of Taipei City with a length of $13 \mathrm{~km}$; The northern section ranged northward from Beitou District of Taipei City to Jinshan District of New Taipei City with a length of $21 \mathrm{~km}$ [4]. The most recent active time of the Sanchiao fault may have been more than 10,000 years, provisionally classified as active fault of category II [4]. The Hukou fault, which is a reverse fault, direction of east-northeast, extending eastward from the Hukou, Hsinchu County to Pingjhen, Taoyuan County, with a length of $21 \mathrm{~km}$. The aging result from the Hukou platform indicate that the Hukou fault may have been active at least 70,000 years ago, temporarily classified as active fault of category II [4].

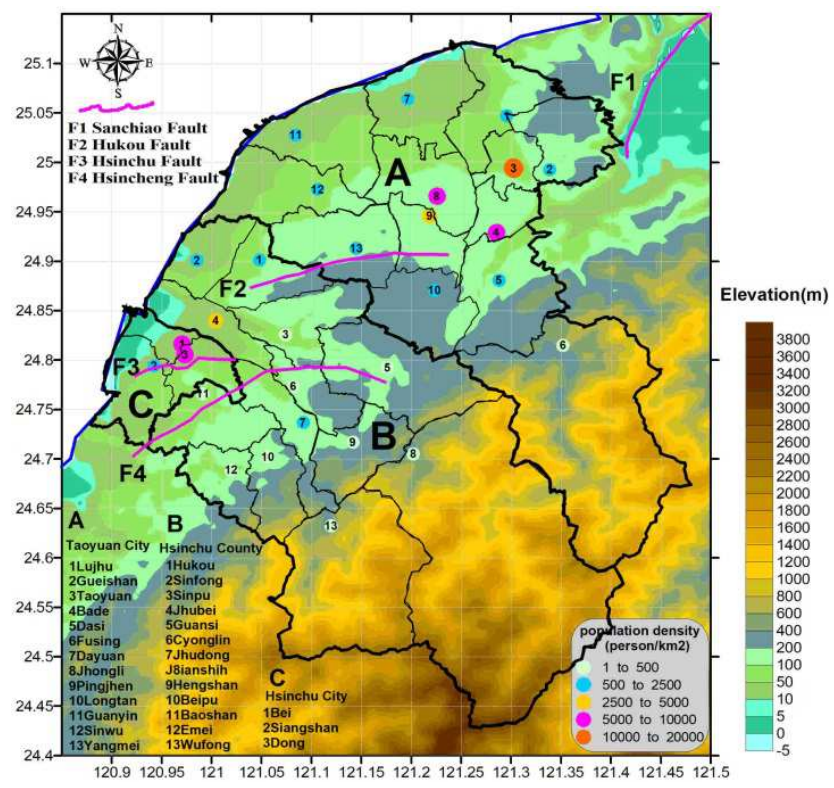

Figure 1. Topographic map of the Hsinchu and Taoyuan area, showing the four active faults (mapped by the Taiwan CGS) and these administrative districts in Taoyuan City, Hsinchu County and Hsinchu City.

Hsinchu Fault, a reverse-slip fault, extends from the west of Hsinchu City to the south bank of Toucian River, about east-west direction with a length of $9 \mathrm{~km}$. Geodesy results 
show that the horizontal displacement velocity on both sides of the fault does not change significantly, but there is a right slip trend. The Hsinchu fault may cut through the late Pliocene stratigraphic accumulation layer and temporarily classified as active fault of category II [4]. Hsincheng fault, a reverse fault, according to geological characteristics are divided into two sections: the northern section is the northeast eastward direction, extending from Toucian River of Cyonglin Township, Hsinchu County to the south of Guansi Township with a length of $12 \mathrm{~km}$; The southern section is northeastwards, extending southward from the Toucian River of Jhudong Township, Hsinchu County to the northeast of Toufen Township, Miaoli County, with a length of about $16 \mathrm{~km}$. The Step Gravel Layer of the Hsincheng Fault Cut-off age about 270 years ago, is a reverse slip fault that is still active in the Holocene and is classified as the active fault of category I. [4].

In terms of geographical location, Taoyuan City is located in northwest Taiwan, east of the Taiwan Strait, the coastline slightly protruding from the arc; the remaining three adjacent sides are land boundaries, northeast, southeast and southwest sides with New Taipei City, Ilan County and Hsinchu County, respectively. The terrain presents a narrow shape from northwest to southeast, the jurisdiction has a continuous hilly platform, land area of about $1,180 \mathrm{~km}^{2}$, a total of 13 administrative districts, of which the largest administrative district is Fusing District, an area of $330 \mathrm{~km}^{2}$, about one-third area of the Taoyuan City; The smallest administrative district is the Bade District, covering an area of $33 \mathrm{~km}^{2}$. The city has 7 municipal rivers. The Dahan river from Shimen Reservoir through the northeast of Dasi District, divided the Taoyuan City into two parts of the southeast and northwest, the southeast is more than 300 meters high hills, steps and mountains. The city's terrain gradually rising to the southeast, steep mountains, narrow valleys; the terrain in the northwest is relatively flat, the platform and the steps are very developed, and the rivers are short and radioactive into the sea [1]. Taoyuan City currently has 13 districts, including Lujhu District, Gueishan District, Taoyuan District, Bade District, Dasi District, Fusing District, Dayuan District, Jhongli District, Pingjhen District, Longtan District, Guanyin District, Sinwu District, Yangmei District. According to the city's Civil Affairs Bureau as of the end of December 2018, the total number of people living in the city now amounted to more than 2.22 million [1].

Hsinchu County is located in northwest Taiwan, south of Taoyuan City, north of Miaoli County, east of the Taiwan Strait, west of the Snow Mountain and Taiba Tsim Mountain. The total land area of the county is $1,427 \mathrm{~km}^{2}$, of which the flat township area is $672 \mathrm{~km}^{2}$, accounting for $47.09 \%$ of the county's total area, and the mountain township area is $755 \mathrm{~km}^{2}$, accounting for $52.91 \%$. The terrain of the county, except Fengshan River and Toucian River for all-in-all flood plains, mostly hills, platforms and mountains, from the southeast to the northwest lower, to the Jhubei City near only elevation of 20-30 meters. Hsinchu County has a total of 13 townships and cities, including Hukou Township, Sinfong Township, Sinpu Township, Jhubei City, Guansi Township, Cyonglin Township,
Jhudong Township, Jianshih Township, Hengshan Township, Beipu Township, Baoshan Township, Emei Township and Wufong Township. The total population of the county is 555,074 (counted until the end of July 2018); Population density of about 388.8 persons per $\mathrm{km}^{2}$, the population is concentrated in Jhubei City, Jhudong Township, Hukou Township and Sinfong Township. The largest population increase in the county in the past ten years is Jhubei City, which is much larger than the population growth rate of the county, and the population aggregation shows the degree of urbanization [2]. In terms of terrain distribution in Hsinchu County, located on the west side of the Central Mountain Range, the terrain is gradually lower extending from the southeast of the county to the northwest, the mountains are folding in the southeast. The Hsinchu County has more hills, lack of vast plains. Due to the complex terrain, can be divided into four types: the mountain area distributed in the three sides around Hsinchu County of $1,427 \mathrm{~km}^{2}$, of which the proportion of mountain areas accounted for $50 \%$ of the county area, hilly areas about $30 \%$, platforms about $10 \%$ and plains about $10 \%$.

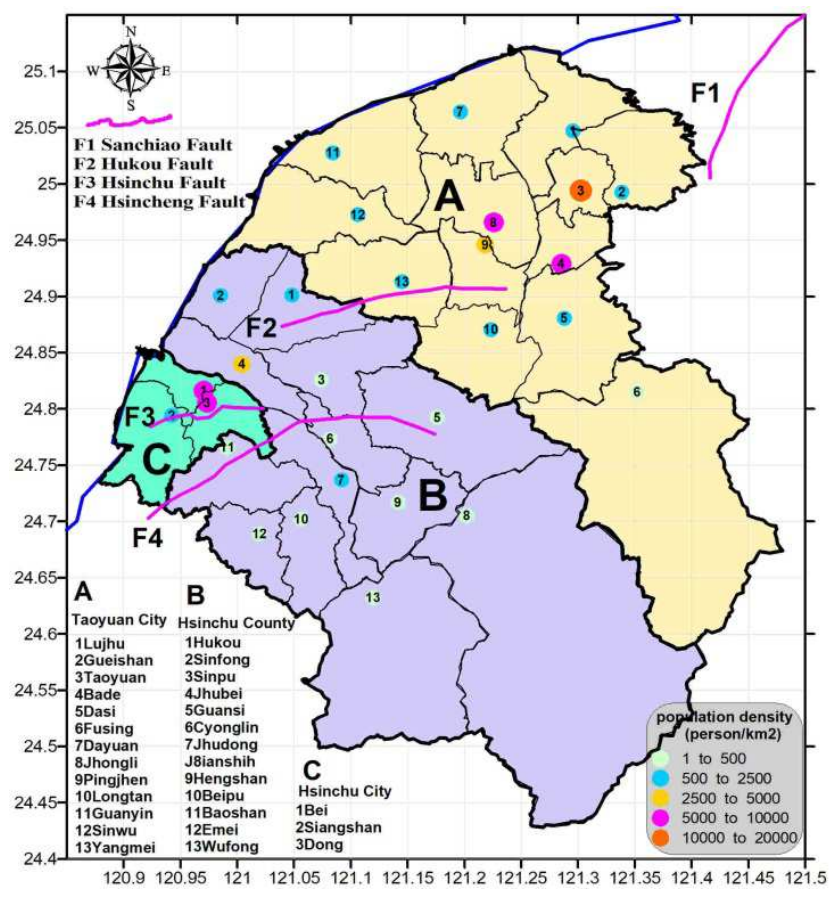

Figure 2. Population density map of the Hsinchu and Taoyuan area. The four active faults and the corresponding administrative districts are also shown.

Hsinchu City is located in the northwest of Taiwan. The city has the Hsinchu Plain, is the most prosperous area of the Hsinchu area. The terrain of Hsinchu City is mostly flat, elevation generally below 100 meters, the terrain of the southeast part of the hilly area is steeper, generally south to north gradually lower. Because the exposed land layer in the hilly area is mainly sloping sand shale inter-layer, the terrain develops into a special fish bone-shaped ridge, which is an important topographical feature of the area. Hsinchu City includes three terrain zones, namely, Hsinchu alluvial plain, Jhunan alluvial plain and Jhudong Hills [3]. Hsinchu City is divided into three districts: North District, Siangshan District 
and East District [3]. The population of the city was 438,524 in May 2017. As a result of the natural environment, most of the population of the city is concentrated in the Hsinchu Plain, especially in the old urban areas with higher population density and lower density of the hilly areas, mostly agricultural population. The city's land area of $104.72 \mathrm{~km}^{2}$, population of 438,524 people, population density of 4187 persons per $\mathrm{km}^{2}$ [3]. The population and population density of the 13 districts of Taoyuan City, 13 districts of Hsinchu County and 3 districts of Hsinchu City are shown in Figure 2 and given in Table 1 [5].

The history of seismic activity in Taiwan dates back to 1604 and has been around for more than 400 years. However, the observation of seismic instruments began with the setting up of seismographs in Taipei in 1897. In this study, seismic activity data from Taiwan since 1683 were used to assess the potential of seismic hazards in Taoyuan and Hsinchu area. The historical earthquake records before 1897 came mainly from government archives and personal diaries. Although the overall record is incomplete, information on earthquake dates, deaths, damage to houses and ground vibrations is provided in the case of disaster earthquakes [6]. In addition, the moment magnitudes of events are based on a database of the National Seismic Data Center on the website of the United States Geological Survey. If there are missing earthquakes in this database, we use the conversion formula for the Richter magnitude to moment magnitude of the earthquake provided by Chen and Tsai (2008) [7]. Overall, the data used by this study include more than 2,000 shallow earthquakes of magnitude greater than 5.0 (focal depth $\leqq 35 \mathrm{~km}$ ) from 1900 to 2019 and 11 disaster earthquakes from 1683 to $1899[6,8]$ The epicenter distribution of these earthquakes is shown in Figure 3. In addition to seismic data, the study also included Sanchiao fault, Hsincheng fault, Hukou fault and Hsinchu fault to calculate the peak ground acceleration (PGA) and peak ground velocity (PGV) in the Hsinchu and Taoyuan area.

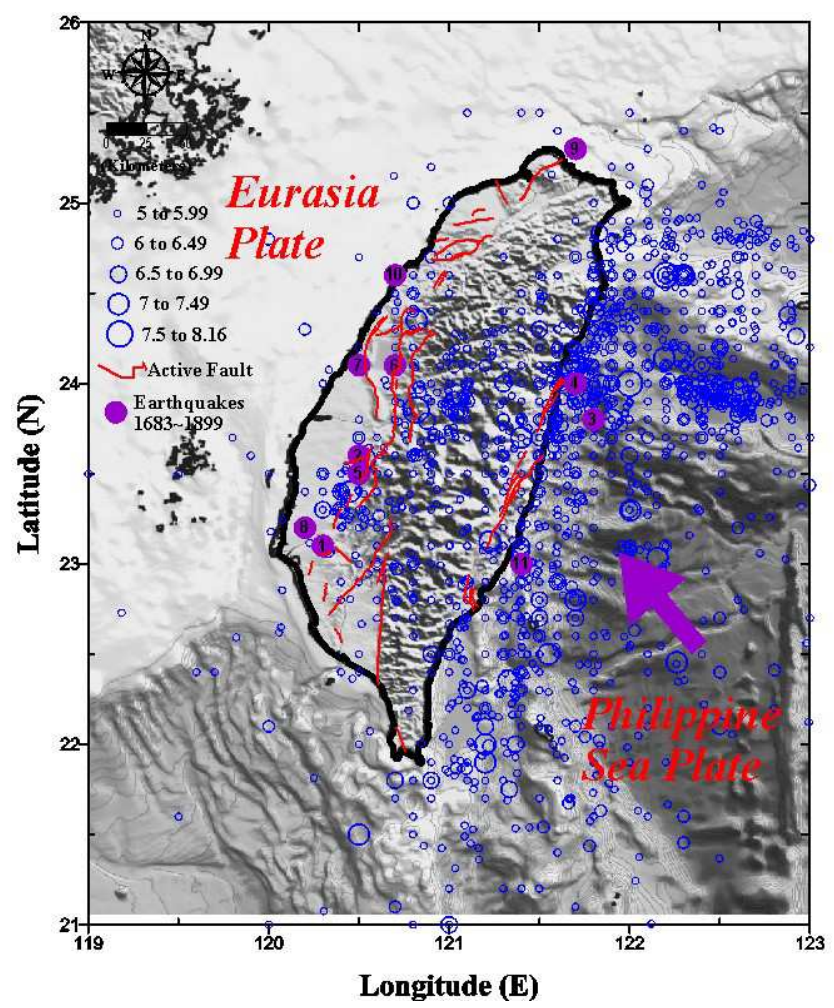

Figure 3. The tectonic setting around Taiwan with earthquakes used in this study. The epicenters of 2159 shallow earthquakes with $M_{w}$ magnitude ranging from 5.0 to 8.2 in 1900-2019 and 11 disastrous earthquakes from 1683-1899 are shown. The base map adopted from National Center for Ocean Research (NCOR) shows the overall plate tectonic environment of Taiwan. The vector of relative motion between the Philippine Sea plate and the Eurasian plate is shown by the arrow. The locations of active faults are also shown.

Table 1. Population and Population density of the administrative districts of Taoyuan and Hsinchu area*.

\begin{tabular}{|c|c|c|c|c|c|c|c|c|c|c|c|}
\hline \multicolumn{4}{|c|}{ Taoyuan City $(2,026,105)$} & \multicolumn{4}{|c|}{ Hsinchu County $(552,169)$} & \multicolumn{4}{|c|}{ Hsinchu City $(441,132)$} \\
\hline No & Region & Pop. & Pop.D. & No & Region & Pop. & Pop.D. & No & Region & Pop. & Pop.D \\
\hline 1 & Lujhu & 161912 & 2144 & 1 & Hukou & 77444 & 1325 & 1 & Bei & 150636 & 9578 \\
\hline 2 & Gueishan & 157633 & 2189 & 2 & Sinfong & 56836 & 1226 & 2 & Siangshan & 77943 & 1421 \\
\hline 3 & Taoyuan & 440840 & 12666 & 3 & Sinpu & 33415 & 463 & 3 & Dong & 212553 & 6330 \\
\hline 4 & Bade & 198074 & 5876 & 4 & Jhubei & 181955 & 3885 & & & & \\
\hline 5 & Dasi & 94451 & 899 & 5 & Guansi & 28896 & 230 & & & & \\
\hline 6 & Fusing & 11505 & 33 & 6 & Cyonglin & 20061 & 492 & & & & \\
\hline 7 & Dayuan & 89281 & 1022 & 7 & Jhudong & 96918 & 1811 & & & & \\
\hline 8 & Jhongli & 405216 & 5296 & 8 & Jianshih & 9543 & 18 & & & & \\
\hline 9 & Pingjhen & 224219 & 4695 & 9 & Hengshan & 13064 & 197 & & & & \\
\hline 10 & Longtan & 121822 & 1619 & 10 & Beipu & 9390 & 185 & & & & \\
\hline 11 & Guanyin & 66472 & 756 & 11 & Baoshan & 14550 & 225 & & & & \\
\hline 12 & Sinwu & 48953 & 576 & 12 & Emei & 5538 & 118 & & & & \\
\hline 13 & Yangmei & 167639 & 1881 & 13 & Wufong & 4559 & 20 & & & & \\
\hline
\end{tabular}

* Note:

(1) Data source: National Statistics (2014)

(2) Pop. = Population.

(3) Pop.D. = Population Density. 


\section{Analysis Method}

\subsection{Maximum Ground Motion Parameters and Seismic Intensity Probability}

In the past, most of the methods of assessing the potential of earthquake hazards were analyzed by the Probabilistic Seismic Hazard Analysis (PSHA) [9]. The basic theory and analysis procedure of this method were first proposed by Cornell [10] in 1968, mainly to assume that the occurrence of earthquakes conforms to the statistical model of Poisson process. The distribution of earthquake numbers and magnitude is in line with the Gutenberg-Richter relationship; the distribution of seismic sources is the normal distribution of point sources. Later, Der Kiureghian and Ang [11] proposed fault rupture models for the Point Source Model of the Cornell method in 1977, to strengthen the situation where the PSHA results in the near fault region are too low due to the fact that the point source pattern may not adequately respond to seismic rupture mechanisms. Der Kiureghian and Ang's fault rupturing patterns have been widely cited by the engineering community until now. In this study, with the actual seismic recording data, do not do the seismic source partition, to use more than 2000 earthquakes calculated seismic intensity probability to estimate the potential of seismic hazards in Taoyuan and Hsinchu area, and the site effect factor included in the estimation model of strong seismic ground motions, we can get closer to the actual situation of the ground motion estimates, in order to more accurately estimate the potential of earthquake hazards [12-18]. In addition to the shallow earthquakes of magnitude greater than 5 mentioned above, this study also includes Sanchiao fault, Hsincheng fault, Hukou fault and Hsinchu fault to calculate with the fault rupture patterns in order to avoid the seismic hazard of underestimating near fault areas by only using point sources.

To sum up, the seismic source area of this study includes the point source and four active faults, the Taoyuan and Hsinchu area are divided to 0.01 degrees (about $1 \mathrm{~km}$ ) as the edge length of each grid point, using the Liu and Tsai [19] attenuation formula to calculate the peak ground acceleration (PGA) and peak ground velocity (PGV) of the grid points, while the study also considers the site effect in order to more accurate response to the real value. The first part of the process estimation is divided into three steps, which explain as follows:

1. At first, we calculate the PGA and PGV caused by each selected shallow earthquake and the above four active faults at each grid point in the Hsinchu and Taoyuan area.

2. Site response factors, including PGA and PGV, are used in this part of the estimate obtained by Liu and Tsai [11] when establishing the attenuation mode in Taiwan. The PGA and PGV site response factor distribution maps in the Hsinchu and Taoyuan area as shown in Figures 4 and 5, respectively. The site response factor is defined here as the residual value (RES) of ground motions, which is the value of the observed logarithm value minus the calculated logarithm value. The magnification value AMP, i.e. AMP = exp (RES), which can be obtained by the site response factor after exponential calculation [20].

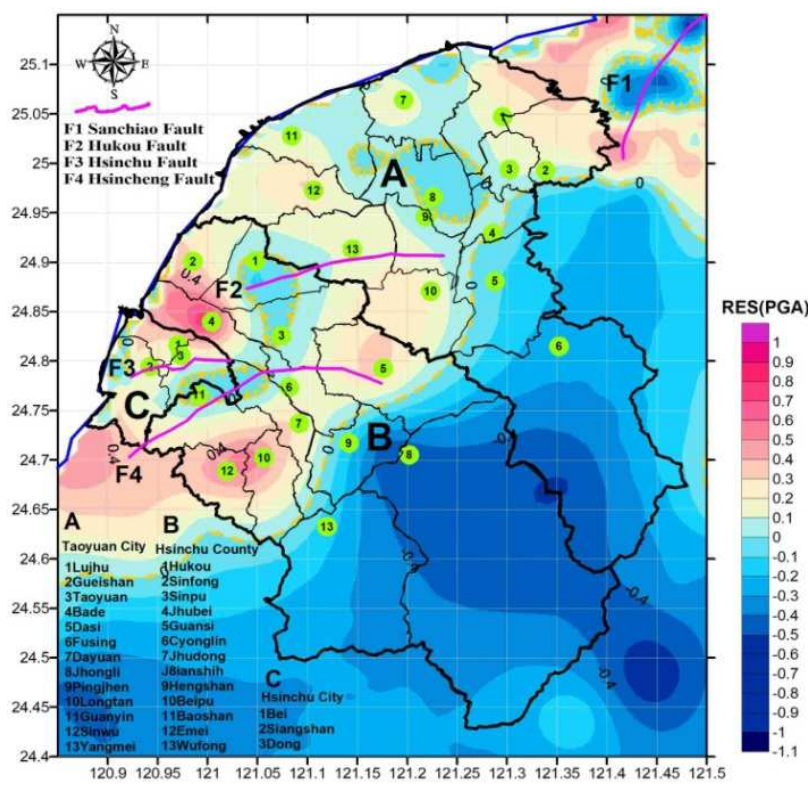

Figure 4. Distribution of the site response factor for PGA in the Hsinchu and Taoyuan area. The site response factor is defined as the residual value $r$ that is the difference between logarithms of the observed and the predicted PGA, The amplification values of site response can be calculated from exp (r).

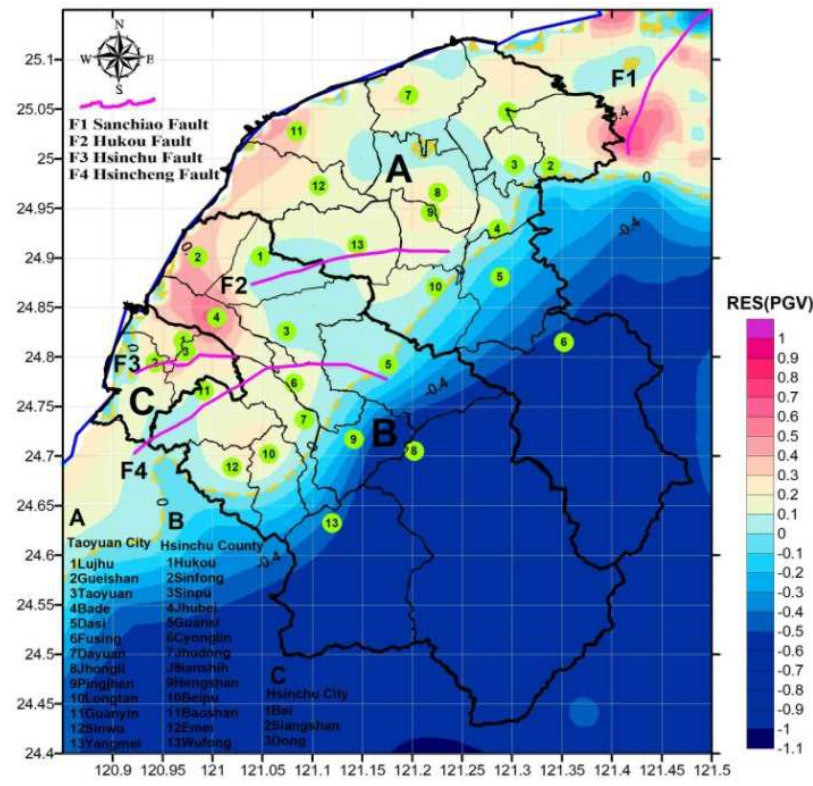

Figure 5. Distribution of the site response factor for PGV in the Hsinchu and Taoyuan area. The site response factor is defined as the residual value $r$ that is the difference between logarithms of the observed and the predicted $P G V$, The amplification values of site response can be calculated from exp (r).

3. The parameters of the attenuation formula used in calculating the maximum ground motion of each grid point are the moment magnitude $(\mathrm{Mw})$, while the distance parameters are using the hypocentral distance, such as the historical earthquake with no source depth data is calculated at a depth of $10 \mathrm{~km}$. In addition, the distance parameter of the active fault is used the shortest distance to the fault plane.

In the second part, we analyze the seismic intensity probability of each grid point. The seismicity intensity probability provides the probability that this grid point may exceed a seismic intensity threshold value over a specific period 
of time. First, calculate the cumulative number of grid points exceeding a ground motion value, divided by the time interval of the seismic data used, and converted to an average annual frequency value that exceeds the ground motion value [21]. The time range of the seismic data used is more than 2000 shallow seismic data with a moment magnitude greater than 5 from 1900 to 2019, with a time interval of 120 years. In addition, 11 disaster earthquakes from 1683 to 1899 were added, with a time interval of 337 years. The average annual frequency value is obtained by the larger value of the two time periods to further calculate the probability of a particular intensity (e.g., the Central Weather Bureau intensity 6 for the PGA of 250 gal) over a selected time period (10,30, and 50 years, respectively) to avoid underestimating the seismic hazard of the grid point.

Next, follow the Poisson probability pattern [22], to get the probability of a selected time period beyond a particular intensity, for example, the seismic intensity probability equation to calculate the $\mathrm{PGA}>250$ gal (relative to $\mathrm{CWB}$ Intensity 6) is as follows:

$$
\mathrm{P}[\mathrm{PGA}>250 \text { gal } \mid \mathrm{t}]=1-e^{-\lambda t}
$$

( $\lambda$ is average annual frequency value exceed the ground motion (PGA250 gal), $\mathrm{t}$ is the time periods $(10,30$, and 50 years, respectively).

In this study, site seismic intensity was used to estimate the potential for seismic hazards in the Hsinchu and Taoyuan area, which has been used worldwide to quantify the degree of vibration and seismic damage [23]. For example, after an earthquake, the United States Geological Survey (USGS) immediately released a ShakeMap to let people know what was shaking around. It provides information that differs from the magnitude and epicenter of an earthquake and focuses on the intensity and extent of damage generated at the site of concern after the earthquake, rather than on the parameters that describe the source of the earthquake. The seismic map released by the CWB is an intensity scale by PGA (Table 2), while USGS ShakeMap uses a Modified Mercalli Intensity (MMI) (Table 3), taking into account the PGA and PGV [24].

In addition to calculating the maximum ground motions of 337 years in the Hsinchu and Taoyuan area, it is also estimated that the seismic intensity probabilities of occurred over 10 years, 30 years and 50 years in the CWB intensity of 5, 6 and 7, and that of the MMI intensity VI, VII, VIII. On the CWB intensity scale (CWBI), the levels of earthquake shaking are designated as minor damage (CWBI V), moderate damage (CWBI VI), and severe damage (CWBI VII). Likewise, On the MMI intensity scale, the levels of earthquake shaking are designated as light damage (MMI VI), moderate damage (MMI VII), and heavy damage (MMI VIII).

Table 2. Central Weather Bureau Intensity Scale (CWBI) of Taiwan.

\begin{tabular}{|c|c|c|c|c|c|c|c|c|}
\hline \multirow{2}{*}{$\begin{array}{l}\text { Intensity } \\
\text { Scale }\end{array}$} & $\mathbf{0}$ & 1 & 2 & 3 & 4 & 5 & 6 & 7 \\
\hline & Micro & Very minor & Minor & Light & Moderate & Strong & Very Strong & Great \\
\hline $\begin{array}{l}\text { Peak Acc. } \\
\left(\mathrm{cm} / \mathrm{s}^{2}\right)\end{array}$ & $<0.8$ & $0.8 \sim 2.5$ & $2.5 \sim 8.0$ & $8 \sim 25$ & $25 \sim 80$ & $80 \sim 250$ & $250 \sim 400$ & $>400$ \\
\hline $\begin{array}{l}\text { Effects } \\
\text { Or Damage }\end{array}$ & & & $\begin{array}{l}\text { Hanging } \\
\text { lamps vibrate } \\
\text { slightly. }\end{array}$ & $\begin{array}{l}\text { Buildings } \\
\text { shake, hanging } \\
\text { objects shake } \\
\text { visibly. }\end{array}$ & $\begin{array}{l}\text { Buildings rock } \\
\text { noticeably; may } \\
\text { cause slight } \\
\text { damage. }\end{array}$ & $\begin{array}{l}\text { Walls crack; some } \\
\text { chimneys and } \\
\text { large archways } \\
\text { topple over. }\end{array}$ & $\begin{array}{l}\text { Damage to some } \\
\text { buildings, doors } \\
\text { and windows } \\
\text { bend. }\end{array}$ & $\begin{array}{l}\text { Severe damage to or } \\
\text { collapse of some } \\
\text { buildings; underground } \\
\text { lines break. }\end{array}$ \\
\hline
\end{tabular}

Table 3. Modified Mercalli Intensity Scale (MMI)

\begin{tabular}{|c|c|c|c|c|c|c|c|c|c|}
\hline $\begin{array}{l}\text { Estimated } \\
\text { Intensity }\end{array}$ & I & II-III & IV & $\mathbf{V}$ & VI & VII & VIII & IX & $\mathbf{X +}$ \\
\hline Peak $\% g$ & $<0.17$ & $0.17-1.4$ & $1.4-3.9$ & $3.9-9.2$ & $9.2-18$ & $18-34$ & $34-65$ & $65-124$ & $>124$ \\
\hline Acc. gal & $<1.7$ & $1.7-13.7$ & $13.7-38.2$ & $38.2-90.2$ & $90.2-176$ & $176-333$ & $333-637$ & $637-1215$ & $>1215$ \\
\hline Peak Vel. $(\mathrm{cm} / \mathrm{s})$ & $<0.1$ & $0.1-1.1$ & $1.1-3.4$ & $3.4-8.1$ & $8.1-16$ & $16-31$ & $31-60$ & $60-116$ & $>116$ \\
\hline Perceived Shaking & Not Felt & Weak & Light & Moderate & Strong & Very Strong & Severe & Violent & Extreme \\
\hline Potential Damage & None & None & None & Very Light & Light & Moderate & Moderate/Heavy & Heavy & Very Heavy \\
\hline
\end{tabular}

\subsection{Assessment of Human Fatality}

The third part of this study will further scenario the earthquake disaster induced by Hsincheng fault of category I in Hsinchu and Taoyuan area. We used the formula between the age distribution and earthquake fatality rate established by Tsai and $\mathrm{Yu}$ [25-26], to estimate the number of people death for future earthquake in the Taoyuan and Hsinchu area, in order to as a reference for prepare earthquake prevention and protection emergency response plan. The formula for this part is as follows:

$$
\mathrm{Y} \%=0.00022 \mathrm{X}^{2}-0.01 \mathrm{X}+0.16
$$

Where $\mathrm{Y} \%$ represents the age-group fatality rate in percentage and $\mathrm{X}$ represents age. The above equation was conducted by $\mathrm{Yu}$ [26] according the total fatalities in individual townships located inside the seismic intensity greater than 250 gals in Nantou and Taichung counties.

\section{Results and Discussion}

This study analyzes the microzonation of seismic hazard potential in Taoyuan and Hsinchu area. The mainly results include (1) the maximum ground motions calculation: we used historical earthquakes and the four active faults, namely Hsincheng fault, Sanchiao fault, Hukou fault and Hsinchu fault 
to calculate the maximum ground motions, including PGA, PGV and MMI in Taoyuan and Hsinchu area. (2) seismic hazard potential: it is also estimated the seismic intensity probabilities in 10 years, 30 years and 50 years over the CWB intensity 5, 6 and 7, and the MMI VI, VII, VIII in Taoyuan City, Hsinchu County and Hsinchu City. (3) Human fatalities estimated from a scenario earthquake by Hsincheng fault.

\subsection{Maximum Ground Motion Parameters (PGA, PGV and MMI)}

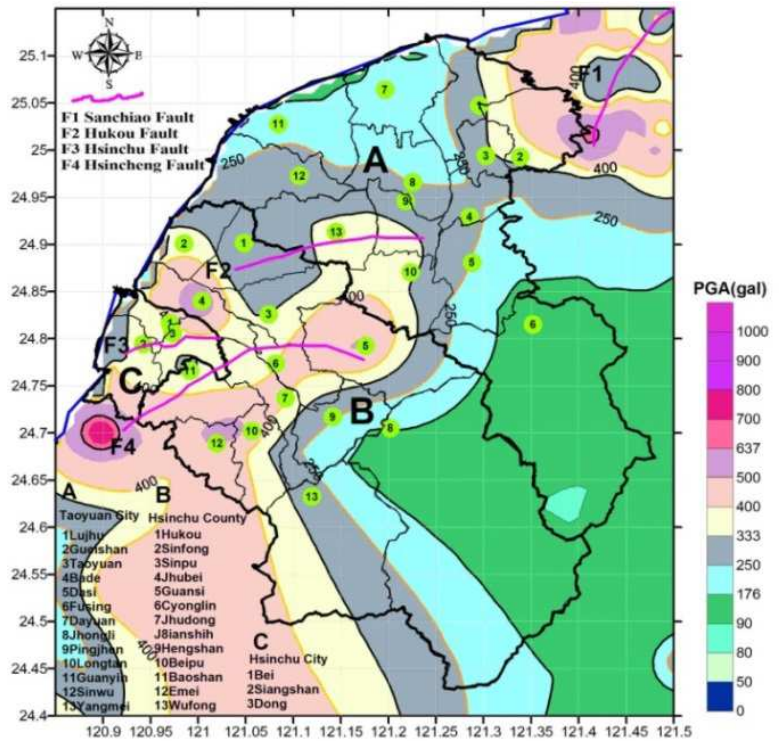

Figure 6. The PGA ShakeMap over a period of 337 years (1683-2019), obtained from 2159 shallow earthquakes with homogenized $M_{w}$ magnitudes ranging from 5.0 to 8.2 in 1900-2019 and 11 disastrous earthquakes from 1683-1899 as well as four active faults in Hsinchu and Taoyuan area. Locations of the corresponding administrative districts and four active faults are also shown.

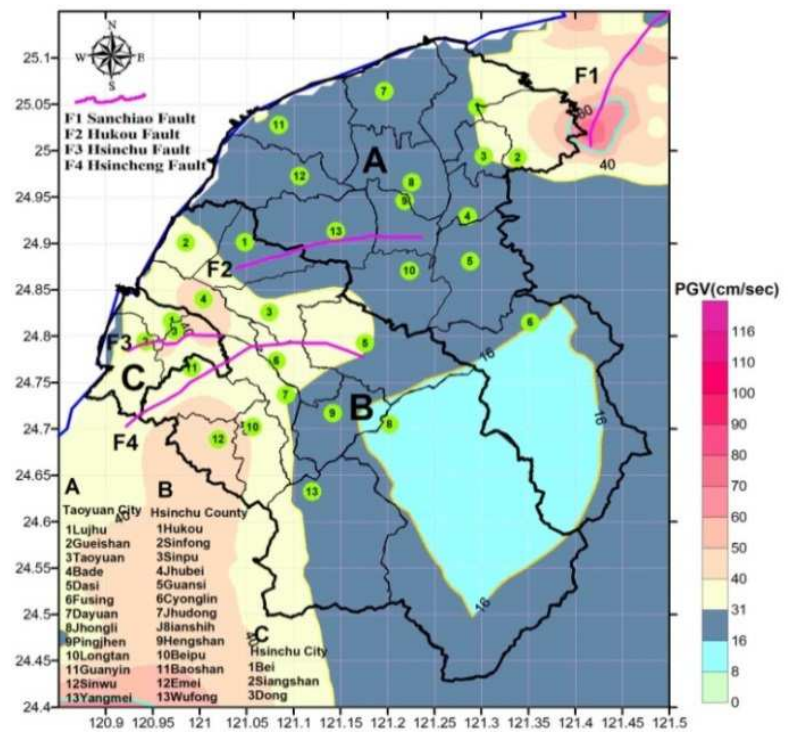

Figure 7. The PGV ShakeMap over a period of 337 years (1683-2019), obtained from 2159 shallow earthquakes with homogenized $M_{w}$ magnitudes ranging from 5.0 to 8.2 in 1900-2019 and 11 disastrous earthquakes from 1683-1899 as well as four active faults in Hsinchu and Taoyuan area. Locations of the corresponding administrative districts and four active faults are also shown.

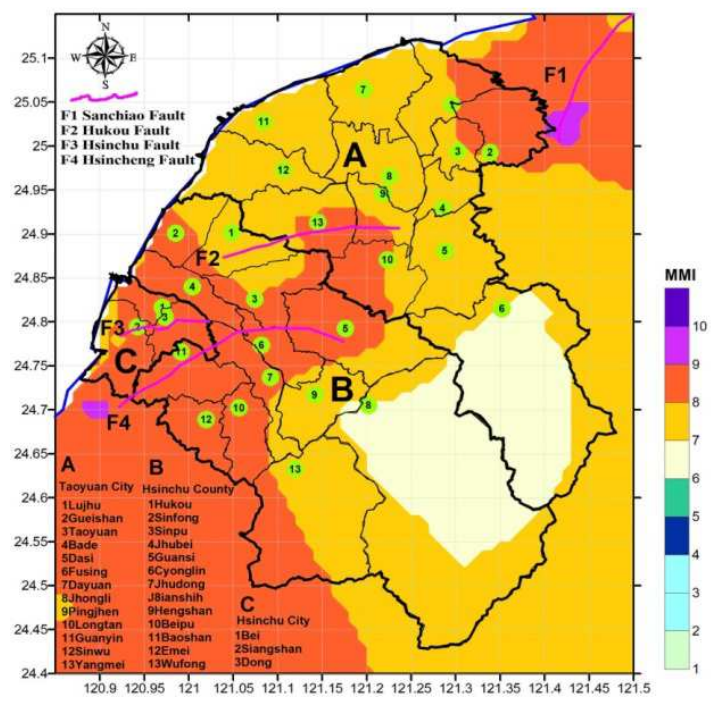

Figure 8. The MMI ShakeMap over a period of 337 years (1683-2019), obtained from 2159 shallow earthquakes with homogenized $M_{w}$ magnitudes ranging from 5.0 to 8.2 in 1900-2019 and 11 disastrous earthquakes from 1683-1899 as well as four active faults in Hsinchu and Taoyuan area. Locations of the corresponding administrative districts and four active faults are also shown.

According to the empirical formula of fault rupture length and seismic moment magnitude by wells and Coopersmith [27], the Sanchiao fault is a normal fault, so the normal fault experience formula is used to estimate the moment magnitude. Mw 6.88 is obtained for the fault rupture length of $34 \mathrm{~km}$. Another Hsincheng fault is an inverse fault, which is estimated by using the inverse fault empirical formula to estimate the moment magnitude. $\mathrm{Mw}$ 6.77 is obtained for the fault rupture length of $28 \mathrm{~km}$. The Hukou fault is an inverse fault, and its seismic moment magnitude is estimated by using the inverse fault empirical formula. Mw 6.61 is obtained for the fault rupture length of $21 \mathrm{~km}$. The Hsinchu fault is an inverse fault, which is estimated by using the inverse fault empirical formula to estimate its seismic moment magnitude. Mw 6.16 is obtained for the fault rupture length of $9 \mathrm{~km}$. The above length of these faults is based on data from the Central Geological Survey (2019) [4].

By the above analysis method, using historical seismic data, that is, from 1900 to 2019,2159 seismic moment magnitude is greater than 5 and the focal depth of shallow earthquake is less than $35 \mathrm{~km}$, plus 11 catastrophic earthquakes from 1683 to 1899 as well as four active faults to calculate the ground motions. The PGA and PGV for 337 years in 13 administrative districts of Taoyuan City, 13 administrative districts of Hsinchu County and 3 administrative districts of Hsinchu City are shown in Figures 6 and 7. Locations of these 29 administrative districts and four active faults are also shown. The PGA contour map from Figure 6 shows that the areas where the PGA is greater than 250 gal (CWB intensity 6) are in the northeastern and northwestern regions of Taoyuan City, the western and northern regions of Hsinchu County, and Hsinchu City. The areas where the PGA is greater than 400 gal (CWB intensity 7) are in the following regions: (1) Southwestern Longtan, Taoyuan City. (2) Southwestern Hukou, southern Sinfong, southeastern Sinpu, northern and 
central Jhubei, northern Guansi, central Cyonglin, central Jhudong, western Beipu, southern Baoshan and Emei. (3) The northeastern Bei District and the northern Dong District, Hsinchu City. Furthermore, the PGV contour map from the Figure 7 shows that the areas where PGV is greater than 31 $\mathrm{cm} / \mathrm{s}$ (MMI VIII) is in the following regions: (1) Southwestern Longtan in Taoyuan City. (2) Southwestern Hukou, southern Sinfong, southern Sinpu, Jhubei, northern Guansi, northern Cyonglin, western and northern Jhudong, Beipu, Baoshan, Emei and western Wufong. (3) Bei District, Dong District, Eastern and Central Siangshan of Hsinchu City. The PGV areas greater than $40 \mathrm{~cm} / \mathrm{s}$ is located in the central Jhubei, western Beipu, southern Baoshan, Emei, and northern and western Dong District of Hsinchu City. Seismic responses to medium- and high-rise buildings in these areas should pay special attention to their earthquake-resistant reinforcement.

Next, we plot the MMI contour map, a combination of the
PGA and the PGV as shown in Figure 8. The MMI VIII areas are shown in the Junction regions of Longtan, Yangmei and Pingzhen, Taoyuan City, as well as the western and central areas of Hsinchu County. MMI VIII, which corresponds to the degree of damage to building materials, low process standards, horizontal resistance to weak type of building heavily damage. The areas of MMI IX are the junction regions of Jhunan and Toufen, Miaoli County and the junction regions of Sinjhuang and Shulin, New Taipei City. MMI IX, which corresponds to the extent of damage to buildings designed not to take into account horizontal direction force buildings seriously damaged, and sometimes collapsed. Poor building materials, low process standards, weak horizontal resistance to the collapse of buildings, buildings may be detached from the foundation. In summary, the ShapeMaps shown in Figures 6-8 can provide critical information to assess potential seismic hazards in Taoyuan City, Hsinchu County and Hsinchu City.

Table 4. The seismic intensity probabilities of exceeded the intensity of Central Weather Bureau (CWB) 5, 6, 7 in 10, 30 and 50 years of the administrative districts of Taoyuan and Hsinchu area*.

\begin{tabular}{|c|c|c|c|c|c|c|c|c|c|c|}
\hline \multirow[t]{2}{*}{ No } & \multirow[b]{2}{*}{ Taoyuan City } & \multicolumn{3}{|c|}{$P[C W B I \geq V](\%)$ in: $(P G A>80$ gal $)$} & \multicolumn{3}{|c|}{$P[C W B I \geq V I](\%)$ in:(PGA $>250$ gal $)$} & \multicolumn{3}{|c|}{$P[C W B I \geq V I I](\%)$ in: $(P G A>400$ gal $)$} \\
\hline & & $10 Y r s$ & 30 Yrs & 50 Yrs & 10 Yrs & 30 Yrs & 50 Yrs & 10 Yrs & 30 Yrs & 50 Yrs \\
\hline 1 & Lujhu & $5-20$ & $20-55$ & $35-75$ & $0-5$ & $0-10$ & $0-15$ & $0-5$ & $0-10$ & $0-15$ \\
\hline 2 & Gueishan & $10-25$ & $25-60$ & $50-75$ & $0-5$ & $5-10$ & $10-15$ & $0-5$ & $0-10$ & $0-15$ \\
\hline 3 & Taoyuan & $5-15$ & $20-40$ & $35-55$ & $0-5$ & $0-10$ & $0-15$ & $0-5$ & $0-5$ & $0-5$ \\
\hline 4 & Bade & $5-15$ & $20-35$ & $35-45$ & $0-5$ & $0-15$ & $0-25$ & $0-5$ & $0-5$ & $0-5$ \\
\hline 5 & Dasi & $5-20$ & $20-45$ & $35-60$ & $0-5$ & $0-15$ & $0-25$ & $0-5$ & $0-5$ & $0-5$ \\
\hline 6 & Fusing & $0-25$ & $5-55$ & $10-75$ & $0-5$ & $0-5$ & $0-5$ & $0-5$ & $0-5$ & $0-5$ \\
\hline 8 & Jhongli & $5-20$ & $20-45$ & $35-60$ & $0-5$ & $0-10$ & $0-15$ & $0-5$ & $0-5$ & $0-5$ \\
\hline 9 & Pingjhen & $10-25$ & $35-60$ & $45-75$ & $0-10$ & $5-20$ & $10-25$ & $0-5$ & $0-5$ & $0-5$ \\
\hline 10 & Longtan & $15-35$ & $40-75$ & $55-90$ & $0-10$ & $10-20$ & $15-30$ & $0-5$ & $0-10$ & $0-15$ \\
\hline 11 & Guanyin & $10-20$ & $30-45$ & $40-55$ & $0-5$ & $0-10$ & $0-20$ & $0-5$ & $0-5$ & $0-5$ \\
\hline 12 & Sinwu & $15-25$ & $35-60$ & $50-80$ & $0-5$ & $0-10$ & $0-15$ & $0-5$ & $0-5$ & $0-5$ \\
\hline \multirow[t]{2}{*}{13} & Yangmei & $10-25$ & $35-60$ & $50-80$ & $0-10$ & $5-20$ & $10-30$ & $0-5$ & $0-5$ & $0-5$ \\
\hline & Hsinchu County & $10 Y r s$ & 30 Yrs & 50 Yrs & 10 Yrs & 30 Yrs & 50 Yrs & $10 Y r s$ & 30 Yrs & $50 \mathrm{Yrs}$ \\
\hline 1 & Hukou & $10-40$ & $35-75$ & $50-90$ & $0-10$ & $5-20$ & $10-35$ & $0-10$ & $0-20$ & $0-30$ \\
\hline 3 & Sinpu & $10-35$ & $35-75$ & $50-90$ & $5-10$ & $15-20$ & $25-30$ & $0-5$ & $0-10$ & $0-15$ \\
\hline 4 & Jhubei & $20-60$ & $50-90$ & $70-95$ & $5-10$ & $10-25$ & $15-40$ & $0-10$ & $0-20$ & $0-30$ \\
\hline 5 & Guansi & $5-40$ & $20-80$ & $35-90$ & $0-10$ & $0-20$ & $0-30$ & $0-5$ & $0-10$ & $0-15$ \\
\hline 6 & Cyonglin & $20-35$ & $50-80$ & $70-90$ & $0-5$ & $5-15$ & $10-25$ & $0-5$ & $0-10$ & $0-15$ \\
\hline 7 & Jhudong & $20-50$ & $40-85$ & $70-90$ & $0-10$ & $5-25$ & $10-35$ & $0-5$ & $0-10$ & $0-15$ \\
\hline 8 & Jianshih & $5-30$ & $5-65$ & $10-85$ & $0-10$ & $5-20$ & $0-30$ & $0-5$ & $0-5$ & $0-5$ \\
\hline 9 & Hengshan & $5-30$ & $15-65$ & $25-85$ & $0-5$ & $0-20$ & $0-30$ & $0-5$ & $0-5$ & $0-5$ \\
\hline 10 & Beipu & $25-65$ & $60-90$ & $80-99$ & $0-10$ & $10-25$ & $15-35$ & $0-10$ & $0-20$ & $0-15$ \\
\hline 11 & Baoshan & $20-55$ & $45-90$ & $70-95$ & $0-20$ & $10-35$ & $15-55$ & $0-5$ & $0-10$ & $0-15$ \\
\hline 12 & Emei & $30-65$ & $60-95$ & $80-99$ & $5-20$ & $20-35$ & $30-55$ & $0-10$ & $5-20$ & $10-35$ \\
\hline \multirow[t]{2}{*}{13} & Wufong & $5-30$ & $20-65$ & $25-80$ & $0-10$ & $0-25$ & $0-35$ & $0-10$ & $0-20$ & $0-35$ \\
\hline & Hsinchu City & $10 Y r s$ & 30 Yrs & $50 Y r s$ & 10 Yrs & 30 Yrs & 50 Yrs & 10 Yrs & 30 Yrs & $50 Y r s$ \\
\hline 1 & Bei & $20-35$ & $45-75$ & $70-90$ & $0-10$ & $5-25$ & $10-35$ & $0-5$ & $0-15$ & $0-20$ \\
\hline 2 & Siangshan & $20-35$ & $35-85$ & $55-95$ & $0-10$ & $5-25$ & $10-35$ & $0-10$ & $0-20$ & $0-35$ \\
\hline 3 & Dong & $20-35$ & $45-70$ & $70-85$ & $0-10$ & $5-25$ & $10-35$ & $0-5$ & $0-10$ & $0-15$ \\
\hline
\end{tabular}

*: The number in normal, bold and italic type in the table represent the low, medium and high potential of earthquake hazard, respectively.

\subsection{Seismic Intensity Probability}

The second part of this study will be based on the above information to estimate the probability of earthquake intensity in Taoyuan and Hsinchu area, including Taoyuan City, Hsinchu County and Hsinchu City in 10, 30 and 50 years beyond the CWB intensity 5, 6, 7 and that of MMI VI, VII and VIII. The results are as follows:
Using historical seismic data and four active faults, we calculate the probability of seismic intensity exceeding CWB intensity 5,6 and 7 over a period of 10,30 and 50 years as shown in Figures 9 (a) (b) (c) to 11 (a) (b) (c) and given in Table 4. The number in normal, bold and italic type in the table represent the low, medium and high potential of earthquake hazard, respectively, and the criteria for distinguishing between the average seismic probabilities in this area are below $25 \%$ 
(inclusive), between $25 \%$ and $75 \%$ (inclusive), and more than $75 \%$. The results show that the area with the highest potential for earthquake hazards in Taoyuan and Hsinchu area is located in the following regions: (1) The area surrounded by Longtan of Taoyuan City, Kansai and Cyonglin of Hsinchu County. (2) The area surrounded by Jhudong, Beipu, Baoshan, Emei, and Dong District of Hsinchu City. (3) The area surrounded by Hukou, Sinfong and Jhubei of Hsinchu County. The corresponding probabilities of earthquake intensity exceeding the CWB intensity 7 during 10,30 and 50 years are $0-10 \%, 5-20 \%$ and $10-30 \%$, respectively. It shows that the longer the period, the higher the probability of earthquake intensity. Furthermore, the earthquake intensity of the CWB intensity 5 during the 10 -year period is greater than $35 \%$ in the following regions: (1) the border area between Longtan and Guansi (2) the area surrounded by Jhudong, Beipu, Baoshan, Emei and Dong District of Hsinchu City (3) the area surrounded by Hukou, Sinfong and Jhubei of Hsinchu County.

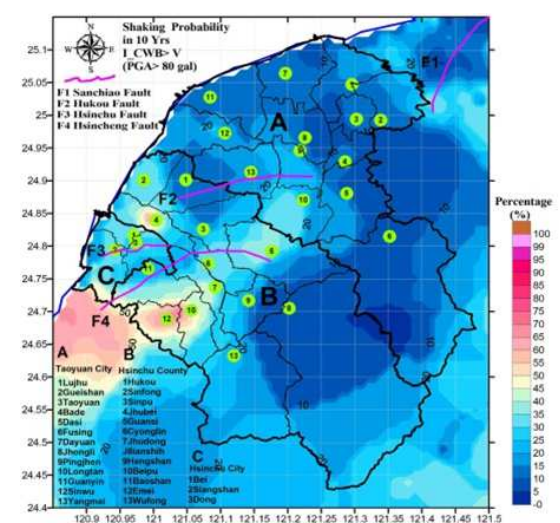

(a)

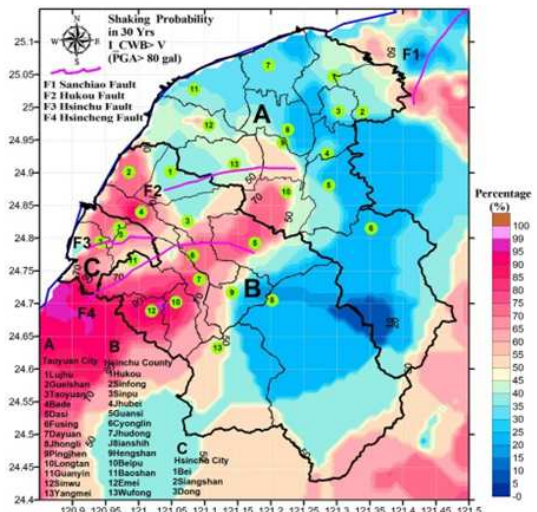

(b)

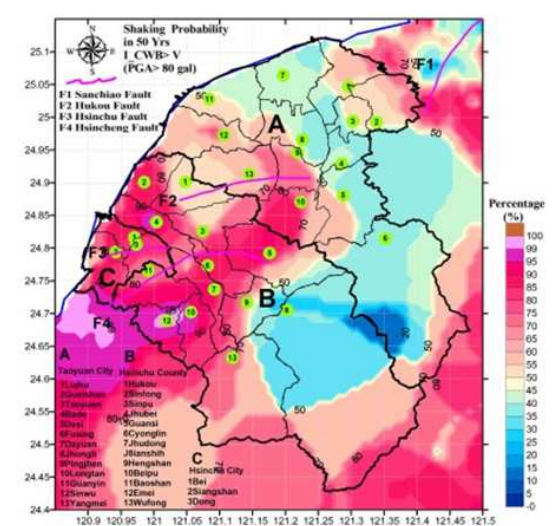

(c)

Figure 9. The distributions of probabilities over 10, 30, and 50-year periods with seismic intensity corresponding to the CWBI V (PGA greater than 80 gal), respectively.

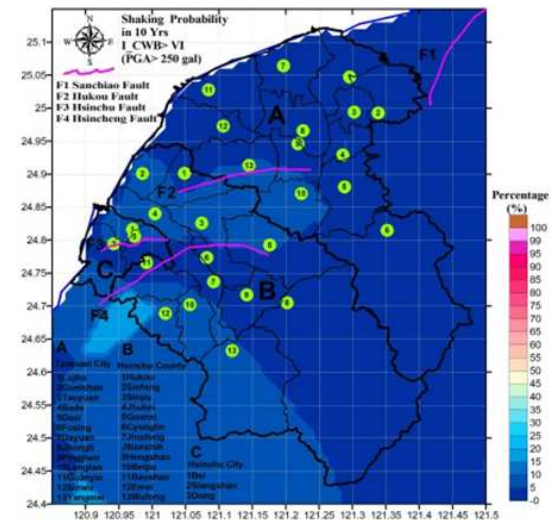

(a)

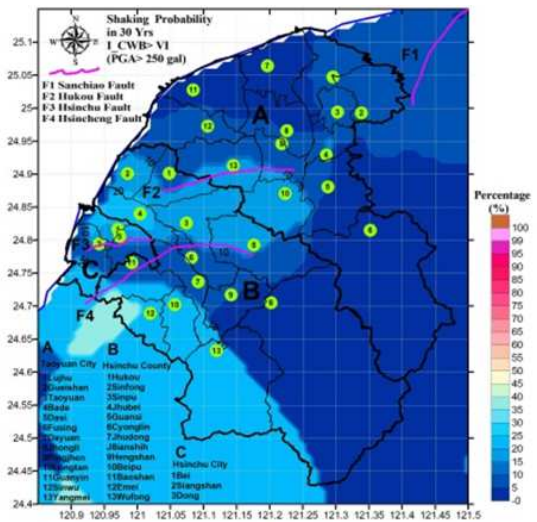

(b)

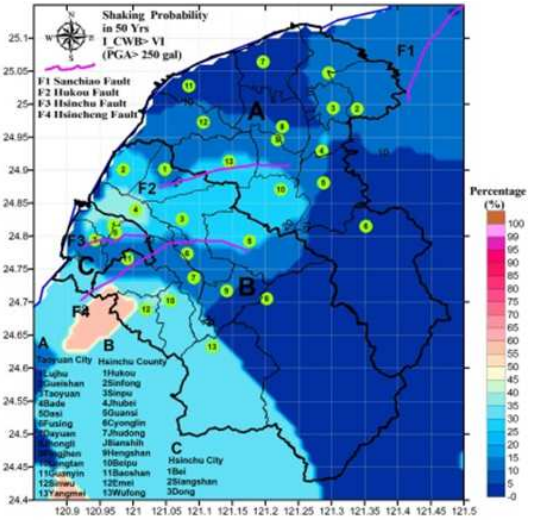

(c)

Figure 10. The distributions of probabilities over 10, 30, and 50-year periods with seismic intensity corresponding to the CWBI VI (PGA greater than 250 gal), respectively.

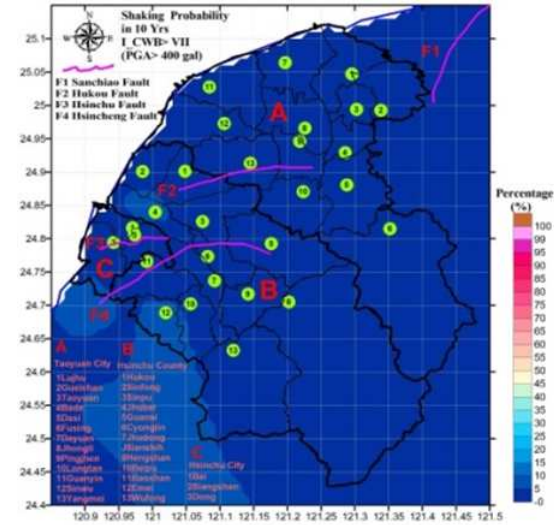

(a)

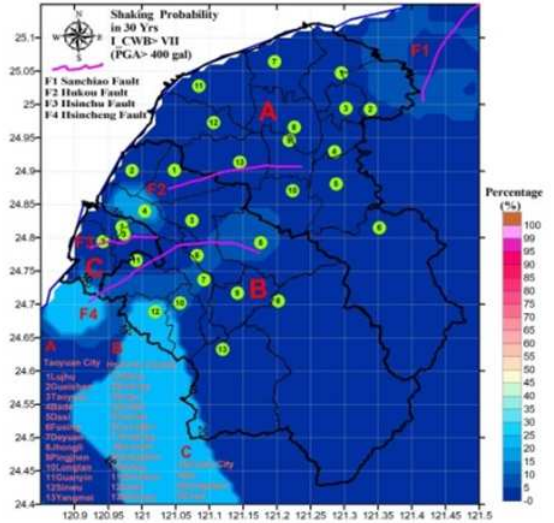

(b)

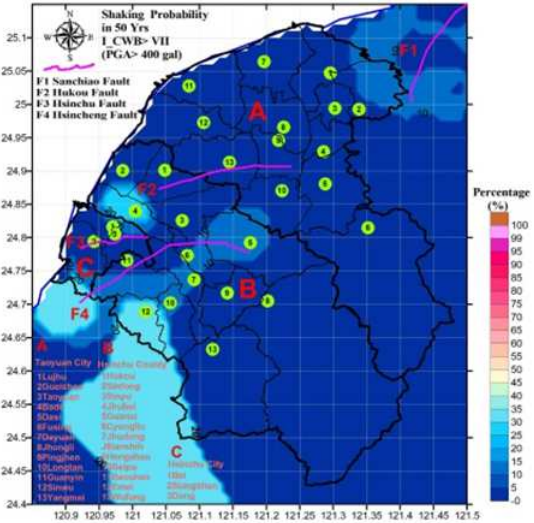

(c)

Figure 11. The distributions of probabilities over 10, 30, and 50-year periods with seismic intensity corresponding to the CWBI VII (PGA greater than 400 gal), respectively. 
In addition, some administrative regions shown by Table 4 have a larger seismic probability cover range, such as the seismic intensity probability of Jianshih exceeding the CWB intensity 5 (PGA $>80$ gal) during 50 years is between $10 \%$ to $85 \%$, and that of Guansi is between $35 \%$ and $90 \%$. In general, three main factors affect the probability of seismic intensity, namely, the location of historical disaster earthquakes, the distance from active faults, and the amplification or attenuation effect of sites. Accordingly, there is a large range of differences in the probability of earthquake intensity in an administrative region, mainly due to site effect and distance from the Hsincheng fault. Therefore, to sum up the results, Table 4 shown the earthquake intensity probability of Taoyuan and Hsinchu administrative district to be used with Figures 9 to 11. Accordingly, the microzonation of seismic hazard potential is not to use the district as a unit. It should be more reasonable subdivided into village.

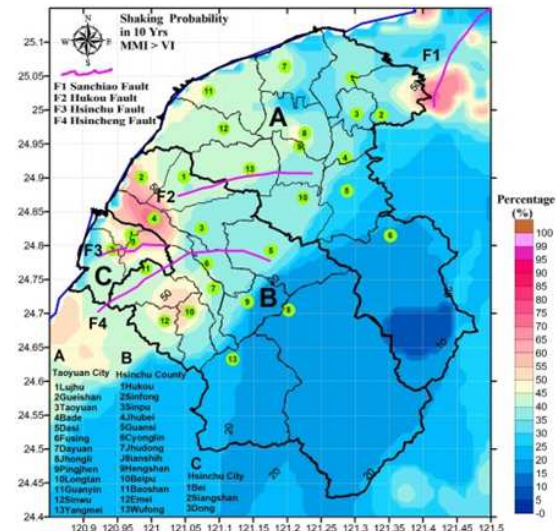

(a)

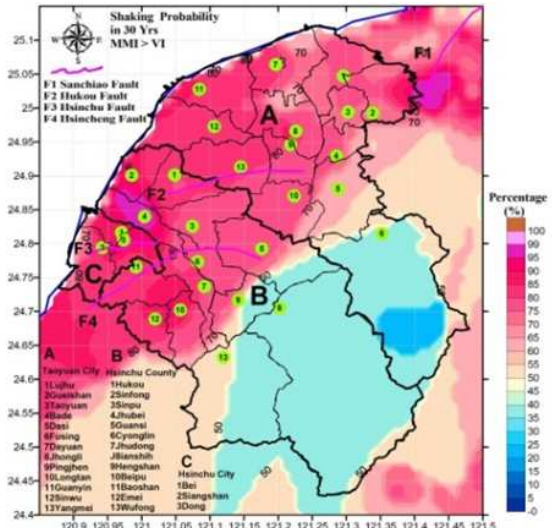

(b)

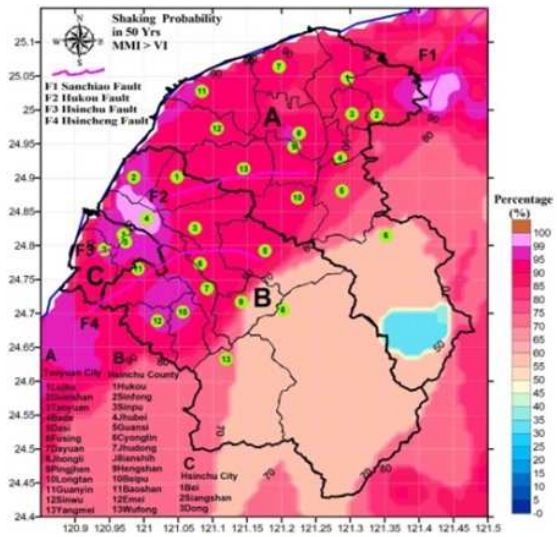

(c)

Figure 12. The distributions of probabilities over 10, 30, and 50-year periods with seismic intensity corresponding to the MMI VI, respectively.

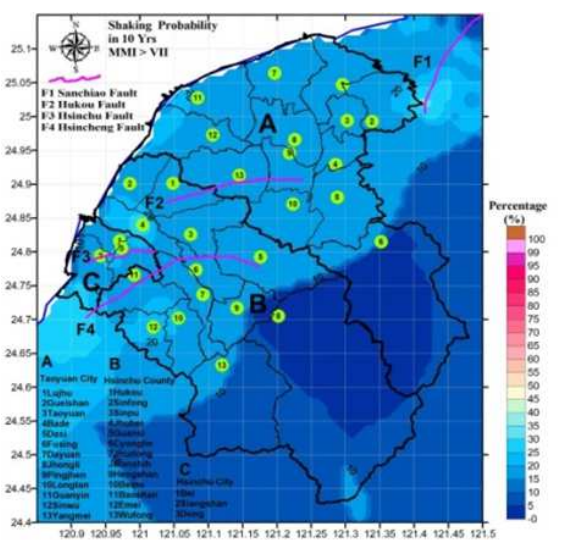

(a)

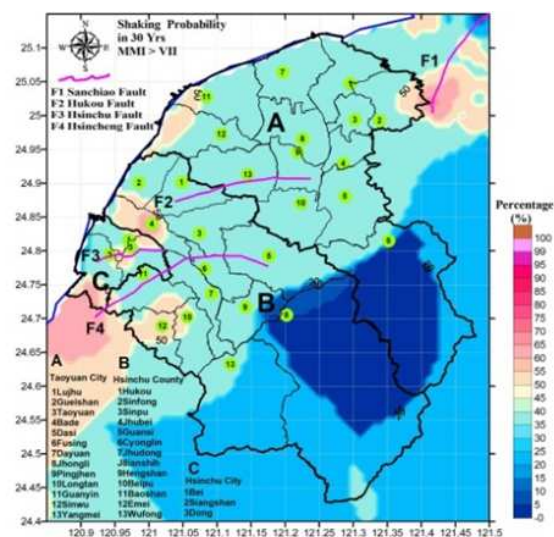

(b)

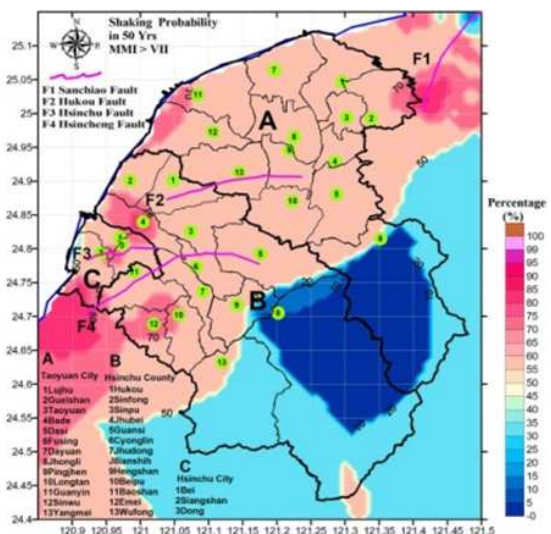

(c)

Figure 13. The distributions of probabilities over 10, 30, and 50-year periods with seismic intensity corresponding to the MMI VII, respectively.

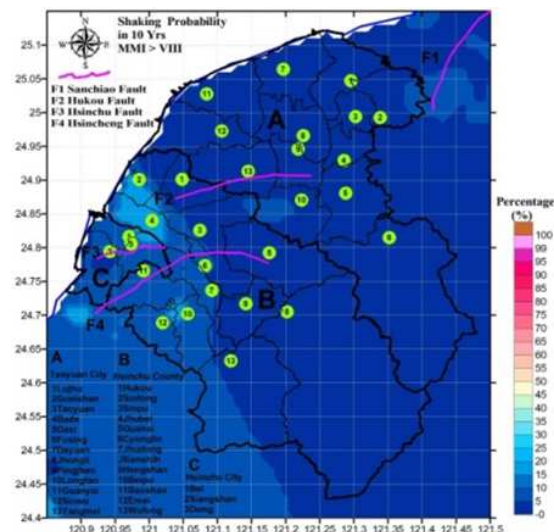

(a)

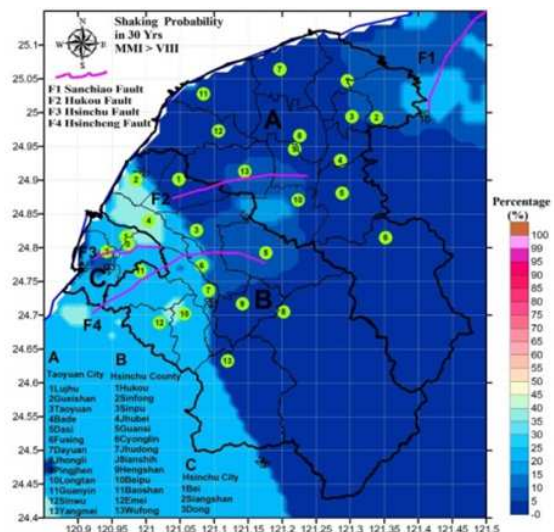

(b)

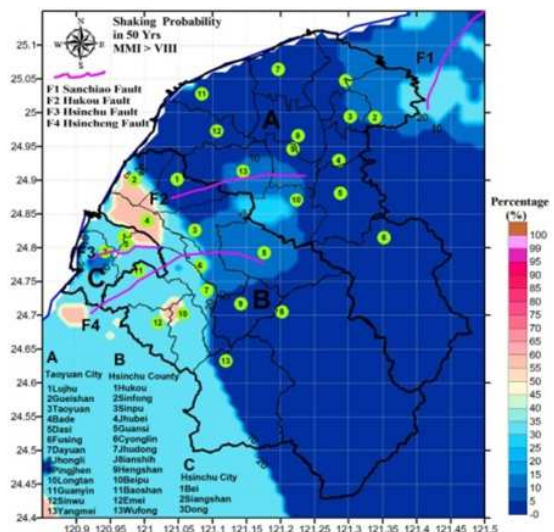

(c)

Figure 14. The distributions of probabilities over 10, 30, and 50-year periods with seismic intensity corresponding to the MMI VIII, respectively. 
Table 5. The seismic intensity probabilities of exceeded the Modified Mercalli Intensity (MMI) VI, VIII and VIII in 10, 30 and 50 years of the administrative districts of Taoyuan and Hsinchu area*.

\begin{tabular}{|c|c|c|c|c|c|c|c|c|c|c|}
\hline \multirow[t]{2}{*}{ No } & \multirow[b]{2}{*}{ Taoyuan City } & \multicolumn{3}{|c|}{$\begin{array}{l}\mathrm{P}[\mathrm{MMI} \geq \mathrm{VI}](\%) \text { in: }(\mathrm{PGA}>90 \text { gal } \\
\text { or } \mathrm{PGV}>8.1 \mathrm{~cm} / \mathrm{s})\end{array}$} & \multicolumn{3}{|c|}{$\begin{array}{l}P[M M I \geq V I I](\%) \text { in:(PGA }>176 \text { gal } \\
\text { or } P G V>16 \mathrm{~cm} / \mathrm{s})\end{array}$} & \multicolumn{3}{|c|}{$\begin{array}{l}\text { P }[M M I \geq V I I I](\%) \text { in: }(P G A>333 \text { gal } \\
\text { or } P G V>31 \mathrm{~cm} / \mathbf{s})\end{array}$} \\
\hline & & $10 \mathrm{Yrs}$ & 30 Yrs & 50 Yrs & $10 \mathrm{Yrs}$ & 30 Yrs & 50 Yrs & $10 \mathrm{Yrs}$ & 30 Yrs & $50 \mathrm{Yrs}$ \\
\hline 1 & Lujhu & $25-40$ & $60-80$ & $80-95$ & $15-20$ & $35-40$ & $55-60$ & $0-5$ & $0-10$ & $0-15$ \\
\hline 2 & Gueishan & $30-70$ & $65-95$ & $85-99$ & $15-25$ & $35-65$ & $55-80$ & $0-10$ & $5-25$ & $10-35$ \\
\hline 3 & Taoyuan & $30-40$ & $70-80$ & $90-95$ & $15-20$ & $35-40$ & $55-60$ & $0-5$ & $0-10$ & $0-15$ \\
\hline 4 & Bade & $25-40$ & $60-80$ & $80-95$ & $15-20$ & $35-40$ & $55-60$ & $0-5$ & $0-5$ & $0-5$ \\
\hline 5 & Dasi & $20-40$ & $40-80$ & $60-90$ & $15-20$ & $35-40$ & $55-60$ & $0-5$ & $0-5$ & $0-5$ \\
\hline 6 & Fusing & $5-25$ & $20-55$ & $35-80$ & $0-20$ & $0-40$ & $0-60$ & $0-5$ & $0-5$ & $0-5$ \\
\hline 7 & Dayuan & $25-45$ & $60-85$ & $80-95$ & $15-20$ & $35-40$ & $55-60$ & $0-5$ & $0-5$ & $0-5$ \\
\hline 8 & Jhongli & $25-50$ & $60-85$ & $80-95$ & $15-20$ & $35-40$ & $55-60$ & $0-5$ & $0-5$ & $0-5$ \\
\hline 9 & Pingjhen & $35-45$ & $75-85$ & $90-95$ & $15-20$ & $35-40$ & $55-60$ & $0-5$ & $0-10$ & $0-15$ \\
\hline 10 & Longtan & $25-40$ & $60-80$ & $80-95$ & $15-20$ & $35-40$ & $55-60$ & $0-10$ & $0-20$ & $0-30$ \\
\hline 11 & Guanyin & $30-45$ & $60-85$ & $80-95$ & $15-25$ & $35-55$ & $55-75$ & $0-5$ & $0-15$ & $0-15$ \\
\hline 12 & Sinwu & $30-45$ & $60-85$ & $80-95$ & $15-25$ & $35-55$ & $55-75$ & $0-5$ & $0-5$ & $0-5$ \\
\hline \multirow[t]{2}{*}{13} & Yangmei & $35-45$ & $75-85$ & $90-95$ & $15-20$ & $35-40$ & $55-60$ & $0-5$ & $0-15$ & $0-20$ \\
\hline & Hsinchu County & $10 \mathrm{Yrs}$ & 30 Yrs & 50 Yrs & 10 Yrs & $30 \mathrm{Yrs}$ & $50 \mathrm{Yrs}$ & $10 \mathrm{Yrs}$ & $30 \mathrm{Yrs}$ & $50 \mathrm{Yrs}$ \\
\hline 1 & Hukou & $40-65$ & $75-95$ & $90-99$ & $15-25$ & $35-55$ & $55-75$ & $0-20$ & $0-35$ & $0-60$ \\
\hline 2 & Sinfong & $40-65$ & $70-95$ & $90-99$ & $15-25$ & $35-55$ & $55-75$ & $0-20$ & $0-35$ & $0-60$ \\
\hline 3 & Sinpu & $35-55$ & $75-90$ & $90-99$ & $15-20$ & $35-40$ & $55-60$ & $0-10$ & $0-25$ & $0-35$ \\
\hline 4 & Jhubei & $35-70$ & $75-95$ & $90-99$ & $15-25$ & $35-65$ & $55-85$ & $5-20$ & $20-40$ & $30-60$ \\
\hline 5 & Guansi & $15-40$ & $40-80$ & $80-95$ & $5-20$ & $20-40$ & $20-60$ & $0-5$ & $0-10$ & $0-15$ \\
\hline 6 & Cyonglin & $35-40$ & $70-80$ & $85-95$ & $15-20$ & $35-40$ & $55-60$ & $0-10$ & $5-25$ & $5-35$ \\
\hline 7 & Jhudong & $35-45$ & $75-85$ & $90-95$ & $15-20$ & $35-40$ & $55-60$ & $0-10$ & $5-25$ & $5-35$ \\
\hline 8 & Jianshih & $15-25$ & $40-55$ & $50-80$ & $0-10$ & $0-25$ & $0-55$ & $0-5$ & $0-5$ & $0-5$ \\
\hline 9 & Hengshan & $15-40$ & $35-80$ & $60-95$ & $0-20$ & $5-40$ & $10-55$ & $0-5$ & $0-10$ & $0-15$ \\
\hline 10 & Beipu & $25-55$ & $50-90$ & $80-95$ & $15-25$ & $35-55$ & $55-75$ & $5-20$ & $20-35$ & $30-60$ \\
\hline 11 & Baoshan & $40-55$ & $80-90$ & $90-95$ & $15-25$ & $35-55$ & $55-75$ & $5-15$ & $20-30$ & $30-60$ \\
\hline 12 & Emei & $30-55$ & $70-90$ & $85-95$ & $15-25$ & $35-55$ & $55-75$ & $5-20$ & $20-35$ & $30-60$ \\
\hline \multirow[t]{2}{*}{13} & Wufong & $15-25$ & $35-55$ & $55-75$ & $5-20$ & $20-40$ & $40-55$ & $0-10$ & $0-25$ & $0-35$ \\
\hline & Hsinchu City & $10 \mathrm{Yrs}$ & $30 \mathrm{Yrs}$ & $50 \mathrm{Yrs}$ & $10 \mathrm{Yrs}$ & $30 \mathrm{Yrs}$ & $50 \mathrm{Yrs}$ & $10 \mathrm{Yrs}$ & $30 \mathrm{Yrs}$ & $50 \mathrm{Yrs}$ \\
\hline 1 & Bei & $30-65$ & $65-95$ & $85-99$ & $10-2010-2015-250$ & $30-50$ & $40-70$ & $5-10$ & $5-30$ & $20-60$ \\
\hline 2 & Siangshan & $30-55$ & $65-90$ & $85-95$ & $10-20$ & $30-50$ & $40-70$ & $0-10$ & $0-25$ & $5-55$ \\
\hline 3 & Dong & $40-65$ & $80-95$ & $90-99$ & $15-25$ & $35-55$ & $55-75$ & $5-15$ & $20-35$ & $25-60$ \\
\hline
\end{tabular}

*: The number in normal, bold and italic type in the table represent the low, medium and high potential of earthquake hazard, respectively.

Similarly, we calculate the probability of earthquake intensity exceeding the MMI VI, VII and VIII over a period of 10,30 and 50 years in 13 administrative districts of Taoyuan City, 13 administrative districts of Hsinchu County and 3 administrative districts of Hsinchu City as shown in Figure 12 (a) (b) (c) to Figure 14 (a) (b) (c) and given in Table 5. MMI VI, VII, VIII, respectively, corresponding to the extent of damage to the building is minor damage, moderate damage and serious damage. The results show that the regions with the highest potential for earthquake hazards in Hsinchu and Taoyuan area are located in the area surrounded by Beipu, Baoshan and Emei of Hsinchu County, as well as the area surrounded by Hukou, Sinfong, Jhubei of Hsinchu County, and Bei Distruct, Xiangshan of Hsinchu City. The corresponding probability of earthquake intensity exceeding MMI VIII during the period of 50 years is above $35 \%$. Furthermore, the regions with high potential for earthquake hazards exceeding the MMI VII are in the area surrounded by Beipu, Baoshan and Emei of Hsinchu County, and the area surrounded by Hukou, Sinfong, Jhubei, Bei District and Siangshan of Hsinchu City as well as the surrounded area by Guanyin, Sinwu and eastern Gueishan of Taoyuan City, the corresponding probabilities of earthquake intensity exceeding MMI VII in 10, 30 and 50 years are above $20 \%, 45 \%$ and $60 \%$, respectively.
In addition, the high earthquake hazard potential areas are also located in the following regions: the area surrounded by Beipu, Baoshan and Emei of Hsinchu County as well as the area surrounded by Hukou, Sinfong, Jhubei of Hsinchu County, and Bei Distruct, Xiangshan of Hsinchu City. The corresponding probabilities of earthquake intensity exceeding MMI VIII in 10, 30 and 50 years are above $10 \%, 25 \%$ and $35 \%$, respectively. The above-mentioned analysis of earthquake hazard potential, which estimates the probability of strong earthquake in Taoyuan and Hsinchu area, can be used as a basis for the development of emergency response plan for earthquake prevention and protection by the central government and local governments.

\subsection{Estimation of Potential Human Fatalities from a Scenario Earthquake}

The third part of this study is to scenario earthquake disaster induced by the Hsincheng fault, using the formula of the age distribution of earthquake deaths established by Tasi and Yu. According to the age distribution of the population in Taoyuan City, Hsinchu County and Hsinchu City, we estimate the death toll that may result from future great earthquakes. By the above analysis method, the linear seismic source pattern of the fault distribution position is used to input the attenuation mode, and 
the site response factor also incorporated to calculate. As a result, the PGA contour map in Taoyuan and Hsinchu area is shown in Figure 15. From Figure 15, the regions of earthquake intensity greater 6 (PGA>250 gal) in Taoyuan City includes the following four partial administrative districts: 1/16 Dasi, 1/20 Fusing, 19/20 Longtan and 1/2 Yangmei. The total population of these jurisdictions is 195,036. According to the formula (2), input the number of people in each age group in the jurisdiction with CWB intensity greater than 6 and the death toll of each age group is obtained as shown in Figure 16 and given in Table 6. In Figure 16, the top panel shows the fatality rates of individual age groups. The middle panel of Figure 16 shows the age distributions of a total population of 195,036 in the towns with estimated seismic intensity PGA greater than 250 gals of Taoyuan City. Finally, the bottom panel in Figure 16 shows the age distributions of 367 fatalities in Taoyuan City. The death toll of all age groups are as follows: 12 persons in the age group of $0-4,10$ persons in the age group of 5-9, 9 persons in the age group of 10-14, 8 persons in the age group of 15-19, 7 persons in the age group of $20-24,7$ persons in the age group of 25-29, 11 persons in the age group of $30-34,14$ persons in the age group of 35-39, 19 persons in the age group of 40-44, 28 persons in the age group of 45-49, 37 persons in the age group of 50-54, 41 persons in the age group of 55-59, 40 persons in the age group of 60-64, 27 persons in the age group of $65-69,26$ persons in the age group of 70-74, 23 persons in the age group of 75-79, 23 persons in the age group of 80-84, 25 persons in the age group greater than 85 . Of these, the number of deaths over the age of 45 exceeded 23 . The relatively high age group of the death toll is in the range of 50 to 64 years old and the death toll was more than 37 .

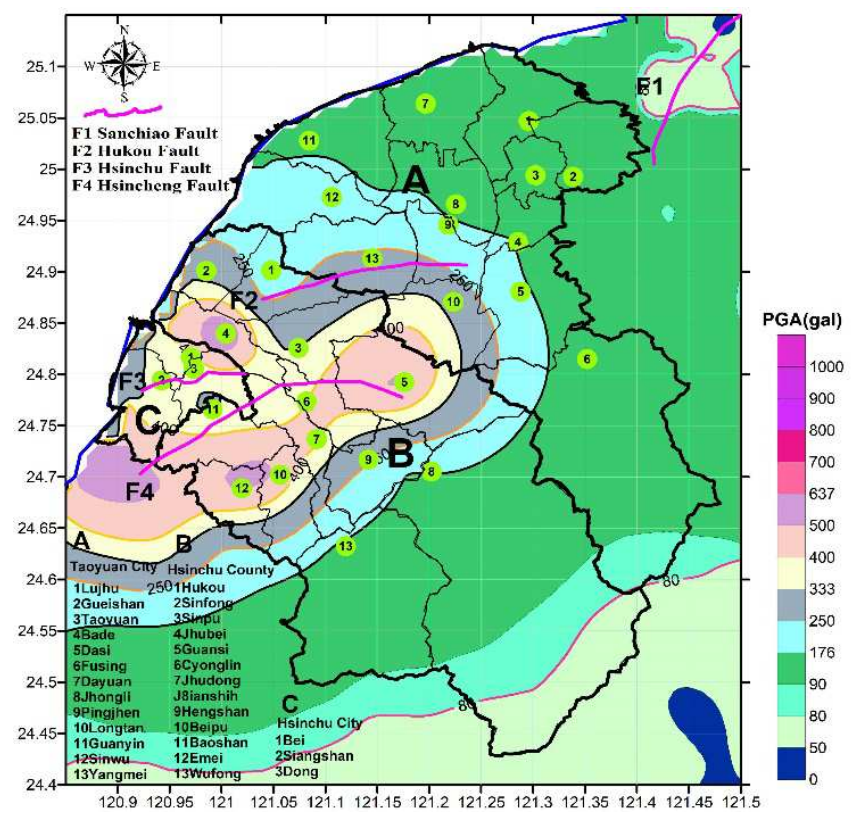

Figure 15. The PGA ShakeMap calculated for an Mw 6.77 scenario earthquake on the Hsincheng active fault.

The areas with intensity great than 6 in Hsinchu County include five administrative districts, that is, Sinpu Township, Jhubei City, Cyonglin Township, Baoshan Township and Emei Township. As well as the following 6 partial administrative jurisdictions: 1/2 Hukou Township, 2/3 Sinfong Township, 9/10 Guansi Township, 7/8 Jhudong Township, 2/5 Hengshan Township and 4/5 Beipu Township. The total population of these jurisdictions is 439,894 . According to the formula (2), input the number of people in each age group in the jurisdiction with intensity greater than 6 . The death toll of each age group is obtained as shown in Figure 17 and given in Table 6 . As a result, the total death toll calculated was 848 in Hsinchu County. The death toll of all age groups is shown in the bottom panel of Figure 17. Of these, the death toll over the age of 40 exceeded 48 . The relatively high age group of the death toll is in the range of greater than 45 years old and the death toll was more than 59.

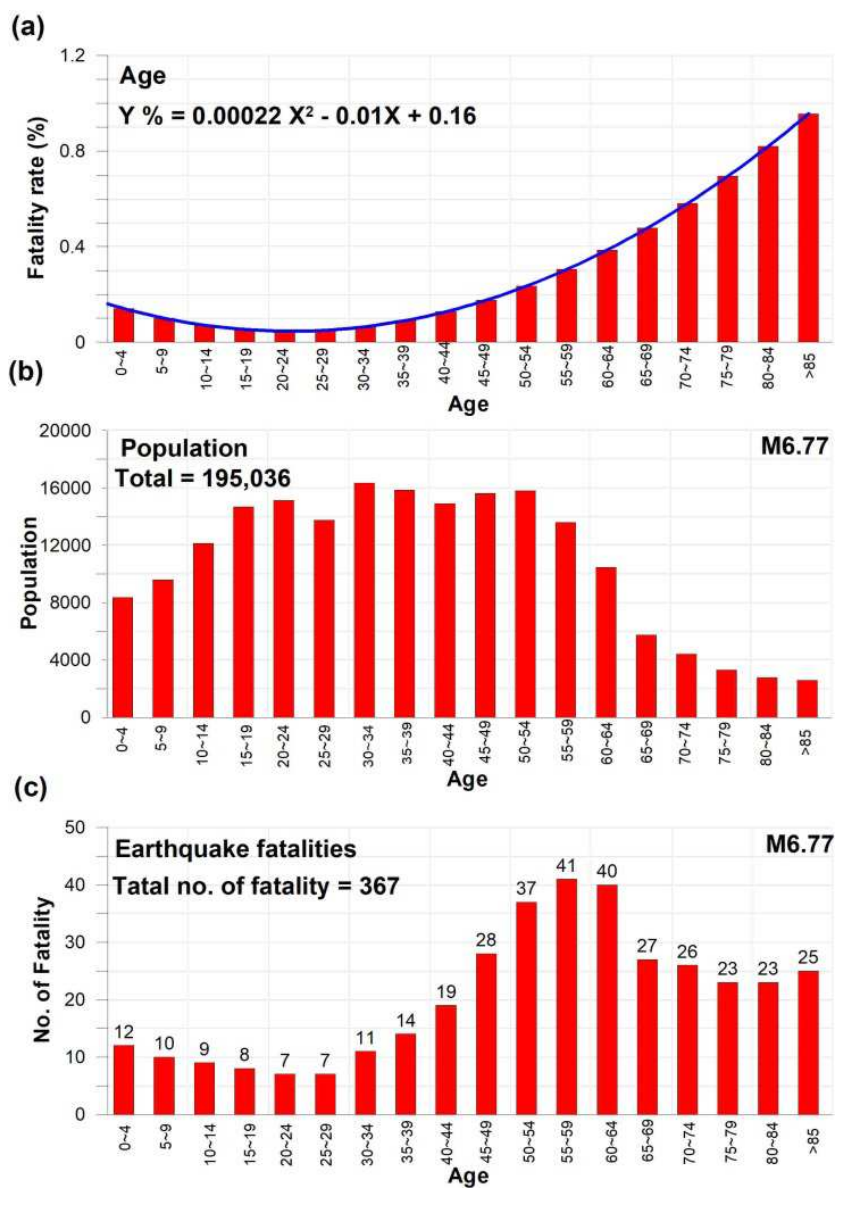

Figure 16. Earthquake fatality rates (top), population (middle), and the number of fatality (bottom) in the Taoyuan City estimated for an Mw 6.77 scenario earthquake on the Hsincheng active fault. A regression equation and corresponding curve on age dependence of the fatality rate is also shown in the top plot.

The area with intensity than 6 in Hsinchu City includes three administrative districts, that is, Bei, Dong and Siangshan districts. The total population of these jurisdictions is 431,029 . According to the formula (2), input the number of people in each age group in the jurisdiction with intensity greater than 6 and the death toll of each age group is obtained as shown in Figure 18 and given in Table 6 . As a result, the total death toll was 809 in Hsinchu City. The death toll of all age groups is shown in the bottom panel of Figure 18. Of these, the death toll 
over the age of 40 exceeded 45 . The relatively high age groups of the death toll are in the age range of 45-79 and the group greater than 85 years old. The corresponding death toll was more than 55. It can be seen that when the earthquake occurred, people of different age groups are significantly different degrees of fatal threat, the threat increased significantly to people with middle age group. It showing that the human do not ignore the middle age group protection during the earthquake.

Table 6. The number of fatality for different age groups in Taoyuan and Hsinchu area estimated for Mw 6.77 scenario earthquakes on the Hsincheng active fault.

\begin{tabular}{|c|c|c|c|c|c|c|c|c|c|c|}
\hline \multicolumn{11}{|c|}{ Taoyuan City } \\
\hline Age & $0 \sim 4$ & $5 \sim 9$ & $10 \sim 14$ & $15 \sim 19$ & $20 \sim 24$ & $25 \sim 29$ & $30 \sim 34$ & $35 \sim 39$ & $40 \sim 44$ & $45 \sim 49$ \\
\hline Number & 12 & 10 & 9 & 8 & 7 & 7 & 11 & 14 & 19 & 28 \\
\hline Age & $50 \sim 54$ & $55 \sim 59$ & $60 \sim 64$ & $65 \sim 69$ & $70 \sim 74$ & $75 \sim 79$ & $80 \sim 84$ & $>85$ & & Total \\
\hline Number & 37 & 41 & 40 & 27 & 26 & 23 & 23 & 25 & & 367 \\
\hline \multicolumn{11}{|c|}{ Hsinchu County } \\
\hline Age & $0 \sim 4$ & $5 \sim 9$ & $10 \sim 14$ & $15 \sim 19$ & $20 \sim 24$ & $25 \sim 29$ & $30 \sim 34$ & $35 \sim 39$ & $40 \sim 44$ & $45 \sim 49$ \\
\hline Number & 34 & 26 & 20 & 16 & 14 & 14 & 24 & 37 & 48 & 59 \\
\hline Age & $50 \sim 54$ & $55 \sim 59$ & $60 \sim 64$ & $65 \sim 69$ & $70 \sim 74$ & $75 \sim 79$ & $80 \sim 84$ & $>85$ & & Total \\
\hline Number & 73 & 78 & 79 & 60 & 73 & 73 & 59 & 59 & & 848 \\
\hline \multicolumn{11}{|c|}{ Hsinchu City } \\
\hline Age & $0 \sim 4$ & $5 \sim 9$ & $10 \sim 14$ & $15 \sim 19$ & $20 \sim 24$ & $25 \sim 29$ & $30 \sim 34$ & $35 \sim 39$ & $40 \sim 44$ & $45 \sim 49$ \\
\hline Number & 36 & 25 & 20 & 15 & 13 & 14 & 25 & 37 & 45 & 59 \\
\hline Age & $50 \sim 54$ & $55 \sim 59$ & $60 \sim 64$ & $65 \sim 69$ & $70 \sim 74$ & $75 \sim 79$ & $80 \sim 84$ & $>85$ & & Total \\
\hline Number & 71 & 80 & 83 & 62 & 62 & 55 & 48 & 58 & & 809 \\
\hline
\end{tabular}

(a)
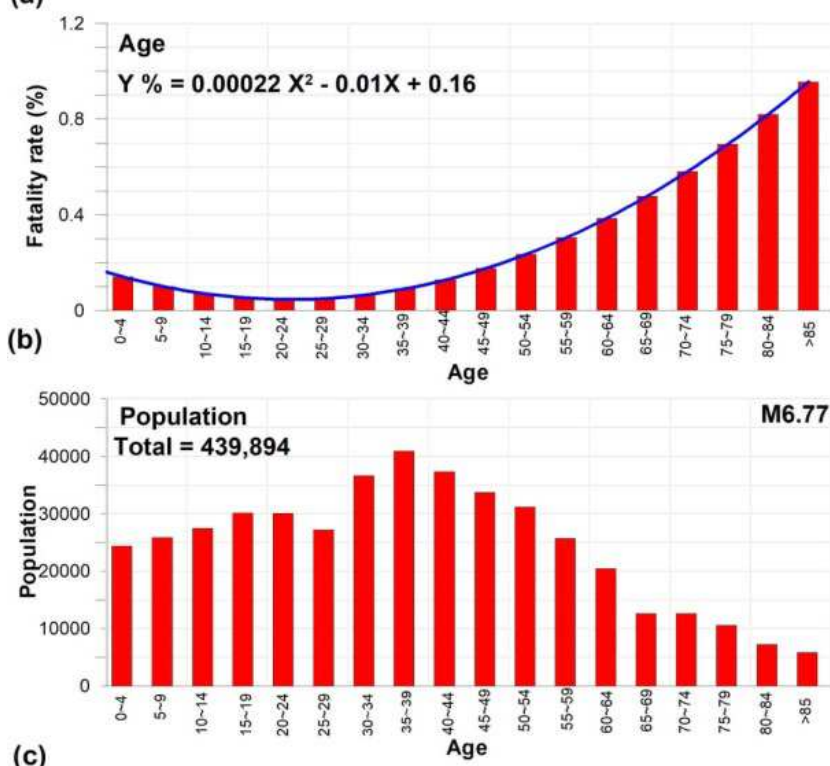

(c)

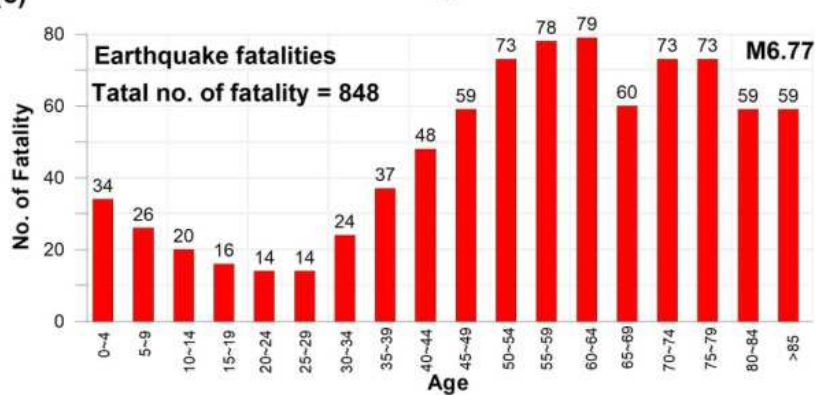

Figure 17. Earthquake fatality rates (top), population (middle), and the number of fatality (bottom) in the Hsinchu County estimated for an Mw 6.77 scenario earthquake on the Hsincheng active fault. A regression equation and corresponding curve on age dependence of the fatality rate is also shown in the top plot. (a)
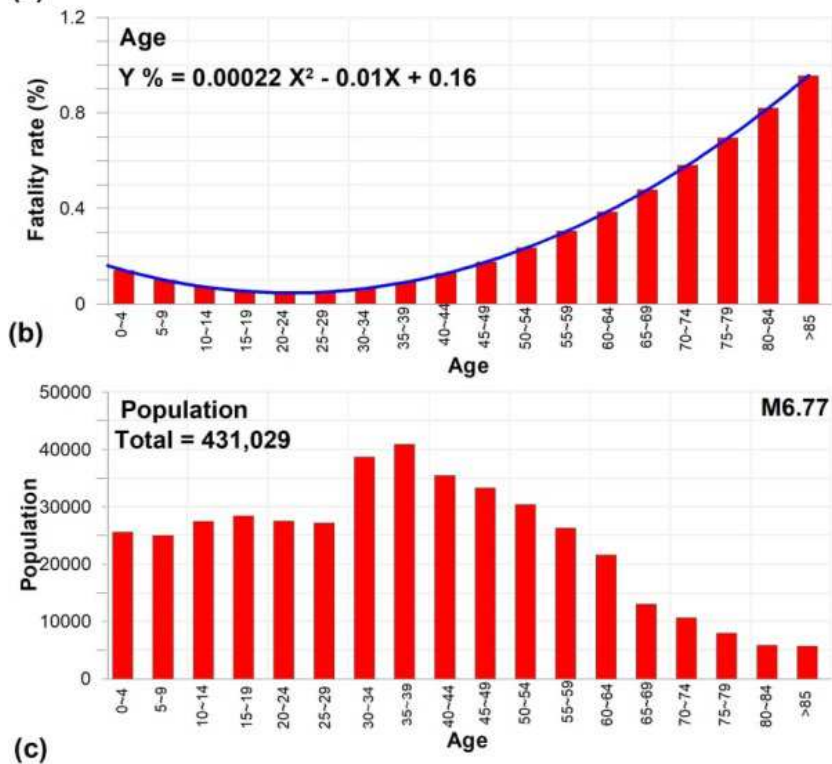

(c)

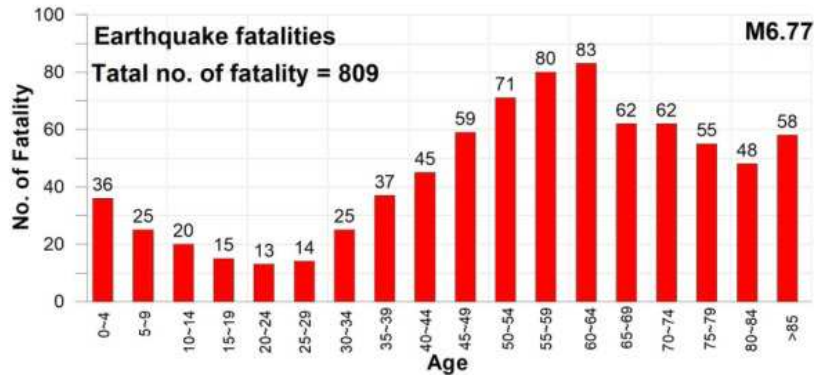

Figure 18. Earthquake fatality rates (top), population (middle), and the number of fatality (bottom) in the Hsinchu City estimated for an Mw 6.77 scenario earthquake on the Hsincheng active fault. A regression equation and corresponding curve on age dependence of the fatality rate is also shown in the top plot.

In summary, we assume a scenario earthquake with $\mathrm{Mw}$ 6.77 on the Hsincheng fault to estimate potential human 
casualties. Especially, the area surrounded by Jhubei of Hsinchu County, Bei District and Dong District of Hsinchu City with both high population density and high site amplification factor for PGA and PGV, as shown in Figures 4 and 5, the local governments should be pay more attention on seismic hazard mitigation in this highly urbanized area with large number of buildings. The results of our study can provide a valuable database for site evaluation of critical facilities in relatively high potential earthquake hazard regions. They also will be useful for land planning. Furthermore, the results will enable both local and central governments in Taoyuan and Hsinchu area to take notice of potential earthquake threat in these areas, as well as to improve decision making with respect to emergency preparedness, response, and recovery activities for earthquakes.

\section{Conclusions}

According to above results and discussion, our findings are summarized as follows:

(1) The PGA contour map using historical seismic data and four active faults to calculate the ground motions shows that the areas where the PGA is greater than 400 gal are in the following regions: (1) Southwestern Longtan. (2) Southwestern Hukou, southern Sinfong, southeastern Sinpu, northern and central Jhubei, northern Guansi, central Cyonglin, central Jhudong, western Beipu, southern Baoshan and Emei. (3) The northeastern Bei District and the northern Dong District. Furthermore, the PGV contour map shows that the areas greater than $40 \mathrm{~cm} / \mathrm{s}$ is located in the central Jhubei, western Beipu, southern Baoshan, Emei, and northern and western Dong District of Hsinchu City. Seismic responses to medium- and high-rise buildings in these areas should pay special attention to their earthquake-resistant reinforcement. In summary, the ShapeMaps shown in Figures 6-8 can provide critical information to assess potential seismic hazards in Taoyuan City, Hsinchu County and Hsinchu City.

(2) Next, we calculate the probability of seismic intensity exceeding CWB intensity 5, 6 and 7 over a period of 10 , 30 and 50 years. The results show that the area with the highest potential for earthquake hazards in Taoyuan and Hsinchu area is located in the following regions: (1) the area surrounded by Longtan, Kansai and Cyonglin. (2) The area surrounded by Jhudong, Beipu, Baoshan, Emei, and Dong District. (3) The area surrounded by Hukou, Sinfong and Jhubei. The corresponding probabilities of earthquake intensity exceeding the CWB intensity 7 during 10,30 and 50 years are $0-10 \%, 5-20 \%$ and $10-30 \%$, respectively.

(3) Similarly, we calculate the probability of earthquake intensity exceeding the MMI VI, VII and VIII over a period of 10, 30 and 50 years show that the regions with the highest potential for earthquake hazards in Hsinchu and Taoyuan area are located in the area surrounded by Beipu, Baoshan and Emei, as well as the area surrounded by Hukou, Sinfong, Jhubei, Bei Distruct and Xiangshan. The corresponding probability of earthquake intensity exceeding MMI VIII during the period of 50 years is above $35 \%$. Furthermore, the regions with high potential for earthquake hazards exceeding the MMI VII are in the area surrounded by Beipu, Baoshan and Emei, and the area surrounded by Hukou, Sinfong, Jhubei, Bei District and Siangshan as well as the surrounded area by Guanyin, Sinwu and eastern Gueishan, the corresponding probabilities of earthquake intensity exceeding MMI VII in 10, 30 and 50 years are above $20 \%$, $45 \%$ and $60 \%$, respectively.

(4) Furthermore, the potential human fatalities were estimated by assuming a scenario Mw 6.77 earthquake on the Hsincheng active fault in Taoyuan City, Hsinchu County and Hsinchu City. As a result, the numbers of fatalities tend to increase rapidly for people above age 45 . The fatalities reached a high peak in age groups of 55-64. Moreover, the fatalities are 367, 848 and 809 in Taoyuan City, Hsinchu County and Hsinchu City, respectively for the scenarios earthquake. It should pay more attention that the people of different age groups are significantly different degrees of fatal threat, the threat increased significantly to people with middle age group.

(5) Finally, the area surrounded by Jhubei of Hsinchu County, Bei District and Dong District of Hsinchu City with both high population density and high site amplification factor for PGA and PGV, the local governments should be pay more attention on seismic hazard mitigation in this highly urbanized area with large number of buildings. The results of our study can provide a valuable database for site evaluation of critical facilities in relatively high potential earthquake hazard regions. They also will be useful for land planning. Furthermore, the results will enable both local and central governments in Taoyuan and Hsinchu area to take notice of potential earthquake threat in these areas, as well as to improve decision making with respect to emergency preparedness, response, and recovery activities for earthquakes.

\section{Acknowledgements}

We thank the Central Geological Survey of Taiwan for providing the faults data. This research was supported by the Ministry of Science and Technology (MOST) of the Republic of China with grant number MOST109-2116-M-244-001.

\section{References}

[1] Taoyuan City Government, 2019: Taoyuan City Disaster Prevention and Relief Plan. Taoyuan: Taoyuan City Government. Retrieved Nov. 25, 2019 from https://cdprc.ey.gov.tw/Page/C10B9C4A41D6D55F/bbe8abce -8f37-40af-8d76-b423384238d4.

[2] Hsinchu County Government, 2018: Hsinchu County Disaster Prevention and Relief Plan. Hsinchu County: Hsinchu County Government. Retrieved Nov. 25, 2019 from https://cdprc.ey.gov.tw/Page/C10B9C4A41D6D55F/267ab24f -909f-4bc5-a93f-0be060e10330. 
[3] Hsinchu City Government, 2017: Hsinchu City Disaster Prevention and Relief Plan. New Hsinchu City: Hsinchu City Government. Retrieved Nov. 25, 2019 from https://cdprc.ey.gov.tw/Page/C10B9C4A41D6D55F/df3426a1 $-7 \mathrm{c} 45-48 \mathrm{a} 0-\mathrm{b} 250-5 \mathrm{c} 064 \mathrm{~b} 789 \mathrm{e} 2 \mathrm{e}$

[4] CGS (Central Geological Survey), 2019: Active fault of Taiwan, Retrieved Dec. 11, 2019 from http://fault.moeacgs.gov.tw/Gis/Home/pageMap?LFun=1.

[5] National Statistics, Republic of China (Taiwan), 2014: Age structure of the resident population by township/city/district. Retrieved Apr. 21, 2014 from http://eng.stat.gov.tw/mp.asp? $\mathrm{mp}=5$.

[6] Tsai Y. B., 1985: A study of disastrous earthquake in Taiwan, 1683-1895; Bull Inst Earth Sci, Acad Sinica 5 1-44.

[7] Liu, K. S., T. C. Shin and Y. B. Tsai, 1999: A free field strong motion network in Taiwan: TSMIP, TAO, Vol 10, No 2 , 377-396.

[8] Chen K. P. \& Y. B. Tsai, 2008: A Catalog of Taiwan Earthquakes (1900-2006) with Homogenized $\mathrm{M}_{\mathrm{w}}$ Magnitudes, Bull. Seis. Soc. Am. 98, 483-489.

[9] Loh, C. H., Yeh, Y. T., Jean, W. Y., \& Yeh, Y. H. (1991). Seismic hazard analysis in Taiwan area using bounded fault-rupture model. Bulletin of the Seismological Society of America, 81 (1), 265-272.

[10] Cornell, C. A., 1968: Engineering Seismic Risk Analysis, Bulletin of the Seismological Society of America, 58, 1583-1606.

[11] Der-Kiureghian, A. \& Ang, A. H-S., 1977: A Fault-Rupture Model for Seismic Risk Analysis, Bulletin of the Seismological Society of America, 67, 1173-1194.

[12] Liu, K. S. and Y. B. Tsai, 2014: Microzonation of Seismic Hazard Potential in Tainan Area, Journal of Architure. 89, 153-176, doi: 10.3966/101632122014090089009

[13] Liu, K. S., and Y. B. Tsai, 2015: Microzonation of seismic hazard potential in Chiayi area. Journal of the Chinese Institute of Civil and Hydraulic Engineering. V 27, No 4, 263-275. doi: 10.6653/JoCICHE.

[14] Liu, K. S. and Y. B. Tsai, 2016a: Microzonation of Seismic Hazards and Assessment of Potential Human Fatality in Chianan Area, Taiwan. Bull. Seismol. Soc. Am. Vol. 106, No1, 141-157, doi: 10.1785/0120150182.

[15] Liu, K. S. and Y. B. Tsai, 2016b: Microzonation of Seismic Hazard Potential in Kaohsiung Area, Journal of Architure. 96, 153-176.

[16] Liu, K. S., 2017, Estimation of Seismic Ground Motions and Attendant Potential Human Fatalities from Scenario
Earthquakes on the Chishan Fault in Southern Taiwan. Terr Atmos. Ocean. Sci.,, Vol. 28, No. 5, 715-737.

[17] Liu, K. S., 2019: Estimation of Seismic Ground Motions and Attendant Potential Human Fatalities from Scenario Earthquakes on the Sanchiao Fault in Taipei City, Taiwan. Earth Sciences, 8, No. 2, 81-93.

[18] Liu, K. S., 2020: Estimation of Seismic Hazard Potential and Attendant Potential Human Fatalities from a Scenario Earthquake on the Sanchiao Fault in Northern Taiwan. Earth Sciences, 9, No. 1, 16-31.

[19] Liu, K. S., \& Tsai, Y. B., 2015: A refined Vs30 map for Taiwan based on attenuation relationships of ground motion. Terr. Atmos. Ocean. Sci., Vol. 26, No. 6, 631-653.

[20] Liu, K. S. and Y. B. Tsai, 2005: Attenuation relationships of peak ground acceleration and velocity for crustal earthquakes in Taiwan, Bull. Seismol. Soc. Am. 95, 1045-1058.

[21] Chiu, J. M., \& Kim, S. G., 2004: Estimation of regional seismic hazard in the Korean Peninsula using historical earthquake data between A. D. 2 and 1995, Bulletin of the Seismological Society of America, 94, 269-284.

[22] Seemann, M., Onur, T., Goltz, J., \& Fenton, J., 2010: Probabilities of significant earthquake shaking in San Francisco bay area communities. Seismological Research Letters, 81, 878-883.

[23] Wald, D. J., V. Quitoriano, T. Heaton, H. Kanamori, C. W. Scrivner, and C. B. Worden, 1999: TriNet "ShakeMaps": rapid generation of instrumental ground motion and intensity maps for earthquakes in Southern California, Earthquake Spectra 15, 537-556.

[24] Wald, D. J., V. Quitoriano, T. Heaton, H. Kanamori, 1999: Relationships between peak ground acceleration, peak ground velocity and Modified Mercalli Intensity in California. Earthquake Spectra 15, 557-564.

[25] Tsai, Y. B., T. M. Yu, H. L. Chao, and C. P. Lee, 2001: Spatial Distribution and Age Dependence of Human-Fatality Rates from the Chi-Chi, Taiwan, Earthquake of 21 September 1999, Bull. Seismol. Soc. Am. 91 1298-1309.

[26] Yu, T. M., 2004: The Relations of Earthquake Disasters with Respect to Surface Fault Rupture, Crustal Movement, and Strong Ground Motion: Using Two Central Taiwan Earthquakes in 1935 and 1999 as Examples. Ph. D. Thesis, National Central University, Chungli, Taiwan, 209 pp. (in Chinese with English abstract).

[27] Wells D. L. and K. J. Coppersmith, 1994: New Empirical Relationships among Magnitude, Rupture Length, Rupture Width, Rupture Area, and Surface Displacement, Bull. Seismol. Soc. Am. 84, 974-1002. 